\title{
Integrating Transcriptomics, Proteomics, and Metabolomics Profiling with System Pharmacology for the Delineation of Long-Term Therapeutic Mechanisms of Bufei Jianpi Formula in Treating COPD
}

\author{
Peng Zhao, ${ }^{1,2}$ Jiansheng Li, ${ }^{1,2}$ Ya Li, ${ }^{1,2}$ Yange Tian, ${ }^{1,2}$ Liping Yang, ${ }^{1,2}$ and Suyun $\mathrm{Li}^{2,3}$ \\ ${ }^{1}$ Henan Key Laboratory of Chinese Medicine for Respiratory Disease, Henan University of Chinese Medicine, \\ Zhengzhou, Henan 450046, China \\ ${ }^{2}$ Collaborative Innovation Center for Respiratory Disease Diagnosis and Treatment \& Chinese Medicine Development of \\ Henan Province, Henan University of Chinese Medicine, Zhengzhou, Henan 450046, China \\ ${ }^{3}$ Department of Respiratory Diseases, The First Affiliated Hospital of Henan University of Chinese Medicine, \\ Renming Road 19, Zhengzhou 450000, China \\ Correspondence should be addressed to Jiansheng Li; li_js8@163.com
}

Received 13 September 2016; Accepted 22 January 2017; Published 23 March 2017

Academic Editor: Nikolaos G. Koulouris

Copyright (C) 2017 Peng Zhao et al. This is an open access article distributed under the Creative Commons Attribution License, which permits unrestricted use, distribution, and reproduction in any medium, provided the original work is properly cited.

In previous work, we identified 145 active compounds from Bufei Jianpi formula (BJF) by system pharmacology and found that BJF showed short-term effect on chronic obstructive pulmonary disease (COPD) rats. Here, we applied the transcriptomic, proteomic, and metabolomics approaches to illustrate the long-term anti-COPD action and its system mechanism of BJF. BJF has obvious antiCOPD effect through decreasing inflammatory cytokines level, preventing protease-antiprotease imbalance and collagen deposition on week 32 by continuous oral administration to rats from weeks 9 to 20. Subsequently, applying the transcriptomic, proteomic, and metabolomics techniques, we detected a number of regulated genes, proteins, and metabolites, mainly related to antioxidant activity, focal adhesion, or lipid metabolism, in lung tissues of COPD and BJF-treated rats. Afterwards, we integrated system pharmacology target, transcript, protein, and metabolite data sets and found that many genes, proteins, and metabolites in rats BJF-treated group and the target proteins of BJF were mainly attributed to lipid metabolism, inflammatory response, oxidative stress, and focal adhesion. Taken together, BJF displays long-term anti-COPD effect probably by system regulation of the lipid metabolism, inflammatory response pathways oxidative stress, and focal adhesion.

\section{Introduction}

Chronic obstructive pulmonary disease (COPD) is a major cause of death with increasing prevalence worldwide, and currently available treatments are largely ineffective $[1,2]$. Traditional Chinese medicinal (TCM) formula has provided an effect treating approach to COPD. It is now well recognized that numerous compounds in herbs could act on different targets and show synergistic and long-term effect on complex disease. Bufei Jianpi formula (BJF), containing twelve Chinese herbs, has been used as a therapeutic agent of
COPD for a long time. In clinical trial, BJF had beneficial effects on measured outcomes in stable COPD patients [3]. We applied systems pharmacology to identify 145 active compounds from BJF and 175 potential targets. Furthermore, we administrated COPD rats with BJF during weeks 9 to 20 and found that BJF had short-term therapeutic effect on COPD rats on week 20 [4]. Evidence from clinical studies suggested that BJF may have long-term effect on COPD. Herein, we aimed to explore the long-term anti-COPD effect and its mechanism of BJF. 
Presently, new approaches allow a complete differential profile including transcriptomic, proteomic, and metabolomic analysis to provide a system level method to investigate the therapeutic mechanisms of TCM formula [57]. Transcriptomics is an efficient approach to detect the gene expression profiling, which may yield further insight into biological process of COPD development and medical intervention [8]. Proteomic profiles help dissect the complexity of therapeutic effect of TCM formula by analyzing protein expression, function, modification, and interactions over temporal scales. Metabolomics refers to the analytical approach used to study different cell products that help to understand the physiological and pathological state, which provide data-rich information of metabolic alterations that reflect genetic, epigenetic, and environmental factors influencing cellular physiology $[9,10]$. Therefore, integrating transcriptomics, proteomics, and metabolomics studies may help us to get a more in-depth understanding of the complex therapeutic processes of TCM formula.

Here, we treated COPD rats with BJF during weeks 9 to 20 and evaluated the long-term anti-COPD effect of BJF on week 32. We then performed transcriptome, proteome, and metabolome analyses to identify differentially expressed genes, proteins, and metabolites. Finally, we integrated our transcriptomic, proteomic, metabolic, and system pharmacology data to uncover significantly perturbed pathways at both the transcript, protein, and metabolite levels and to dissect the long-term anti-COPD mechanism of BJF at system level.

\section{Materials and Methods}

2.1. Chemicals and Animals. Chemicals, such as Klebsiella pneumoniae, tobacco, aminophylline, antibodies, and rats, were prepared as described previously [4]. The animal facilities and protocols were used with the permission of the Experimental Animal Care and Ethics Committee (Henan University of Traditional Chinese Medicine).

2.2. COPD Rat and BJF Administration. COPD rats and BJF formula were prepared as described previously [4]. Normal saline, BJF (4.44 g/ kg), and aminophylline $(2.3 \mathrm{mg} / \mathrm{kg})$ were orally administrated to COPD every day during weeks 9 to 20 . Normal saline was also orally administrated to control rats. The control and COPD rats were anaesthetized and killed to obtain lung tissues and blood on week 32 .

2.3. Pulmonary Function and Histological Analyses [4]. We detected the pulmonary function every four weeks during weeks 0 to 32. Lung tissues were harvested for histological and immunohistochemical examination. The specimens were fixed, embedded, cut into sections, and then stained with hematoxylin and eosin. Immunostaining for interleukin- (IL-) 6 , IL- $1 \beta$, tumor necrosis factor- (TNF-) $\alpha$, soluble TNF- $\alpha$ receptor 2 (sTNFR2), collagen I, collagen III, collagen IV, matrix metalloproteinase- (MMP-) 2, MMP-9, and tissue inhibitor of MMP (TIMP-) 1 followed the methods described previously. The levels of IL- $1 \beta$, IL- 6 , TNF- $\alpha$, and sTNFR2 in sera were analyzed using ELISA kits.

2.4. Gene Expression Analyses. Total RNA was isolated, purified, amplified, and labeled. Finally, the slides were analyzed. Data were collected with Agilent GeneSpring GX software version 11.0 and filtered for significant detection (Student's $t$ test screening, $p<0.05)$ and differential expression versus COPD model rats (fold change, $\mid \log$ ratio $\mid>1$ ).

2.5. Protein Expression Analysis. The lung tissues were lysed and homogenized. The lysates were digested by trypsin solution. Tryptic peptides were labeled. Peptides were fractionated using strong cation exchange fractionation and then used for LC-MS analysis. Fold changes are higher than 1.0 for upregulation or lower than 1.0 for downregulation. Statistical significance was evaluated using one sample $t$-test ( $p$ values $<0.05$, statistically significant).

2.6. Metabolites Analysis. Lung tissue was prepared as previously [11]. The tissue metabolic profiling analysis was conducted. PLS-DA in software SIMCA-P (Ver 11.0, Umetric, Umea, Sweden) was applied to analyze the metabolite profiling [12]. Statistical significance was tested by Student's $t$-test ( $p$ values $<0.05$, statistically significant $)$.

2.7. Gene, Protein, and Metabolite Network Analyses. Cytoscape v3.1.1 plugins, such as BiNGO and CluGO, were used to analyze the molecular function of transcripts and proteins $[13,14]$. Pathway enrichment analysis was performed using the DAVID (regulated pathways, $p$ was $<0.05$ ). Integrated pathway analysis of gene, protein, and metabolomics data was analyzed by Metscape [15]. The most relevant pathways of the metabolites were analyzed using MetaboAnalyst 3.0 [16].

2.8. Statistical Analysis. One-way analysis of variance with the SPSS 19.0 software package (IBM Corporation, Armonk, NY, USA) was applied to evaluate the statistical differences. Values are expressed as mean \pm standard error of mean.

\section{Results}

3.1. Long-Term Effect of BJF on COPD Rats. To investigate the long-term anti-COPD action of BJF, we administrated $\mathrm{BJF}$ to COPD rats during weeks 9 to 20 and tested the effect of BJF on the functional and morphological changes of lung tissues. In Figure 1, compared with the model group, BJF and aminophylline markedly elevated the TV, PEF, and EF50 in COPD rat at week 32. Meanwhile, lung injury scores, bronchiole wall thickness, small pulmonary vessels wall thickness, bronchiole stenosis, and alveolar diameter markedly elevated in the COPD rats and this elevation was significantly inhibited by BJF (Figures 2(a)-2(f)). Reduction of alveolar number in COPD rats was significantly suppressed by BJF (Figure $2(\mathrm{~g})$ ). These findings indicated that BJF showed long-term anti-COPD on COPD rats. 


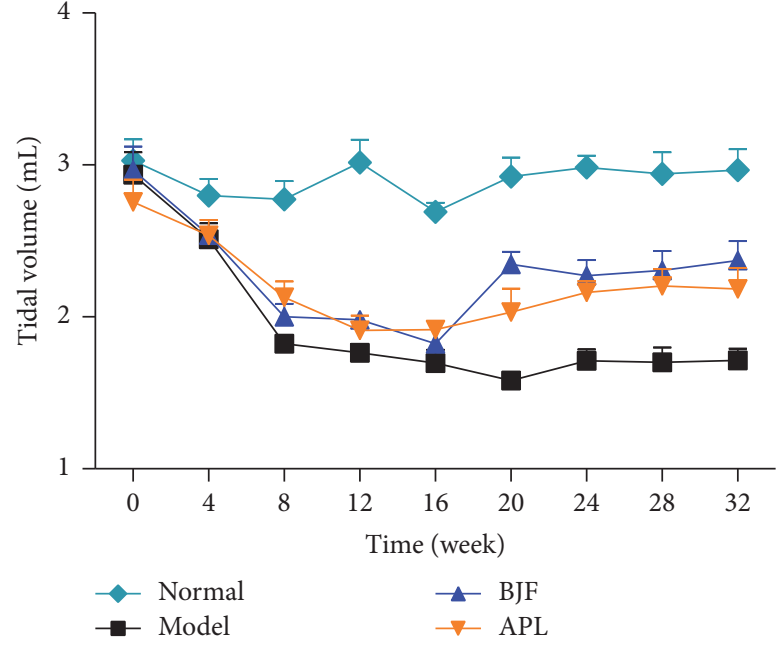

(a)

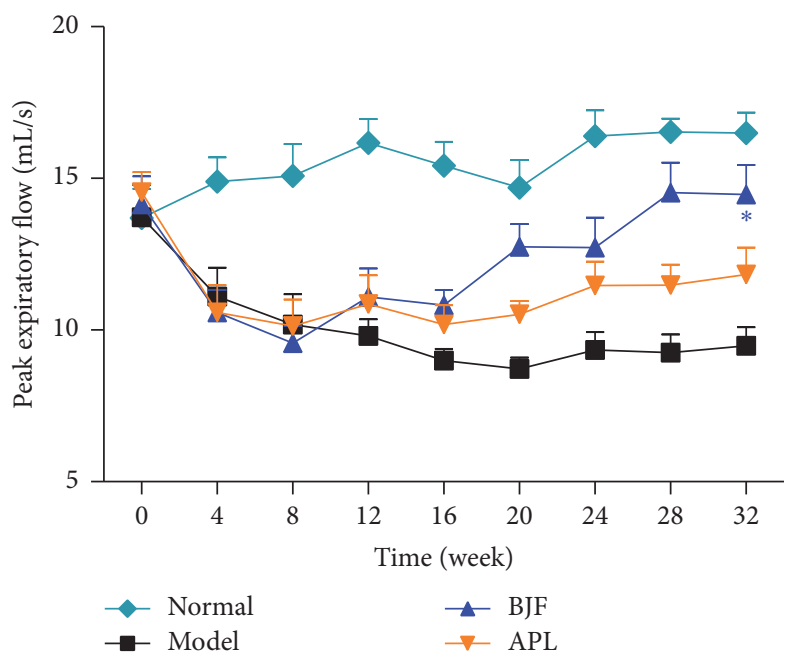

(b)

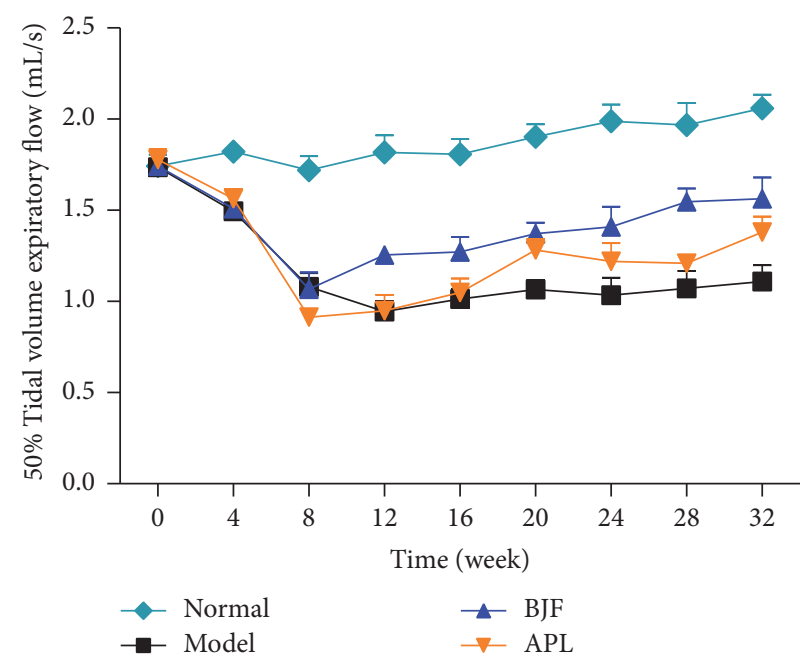

(c)

FIGURE 1: Effect of BJF on the pulmonary function. TV (a), PEF (b), and EF50 (c) were examined every four weeks from weeks 0 to 32 . Results were given as means \pm SEM and ${ }^{*} p<0.05$ versus model.

3.2. Long-Term Effect of BJF on the Inflammatory Responses in COPD Rats. The inflammatory cytokines are the central mediators in many immune-mediated pulmonary diseases, such as COPD [17-19]. Thus, we evaluated the long-term effect of BJF on the expression levels of inflammatory cytokines in the lung and serum. Compared with model rat, BJF and aminophylline significantly suppressed the levels of IL- $1 \beta$, IL- 6 , TNF- $\alpha$, and sTNFR2 in lung tissues on week 32 (Figure 3 ). There are many evidences suggesting the excessive pulmonary inflammation is believed to result in "spill-over" into the systemic inflammation [18]. We then analyzed the levels of IL- $1 \beta$, IL- 6 , TNF- $\alpha$, and sTNFR2 in serum on week 32. We observed BJF treatment significantly decreased these inflammatory cytokines levels in serum (Figure 4).

3.3. Long-Term Effect of BJF on Protease-Antiprotease Imbalance and Collagen Degradation. The protease-antiprotease imbalance and collagen degradation play significant role in the extensive remodeling of lung tissue structure, which is important pathogenesis of COPD [20-22]. Thus, we tested the long-term effect of BJF on MMP-2, MMP-9, TIMP-1, and collagens I, III, and IV expression. In Figure 5, on week 32, the protein levels of MMP-2/-9 were markedly suppressed by BJF treatment, and the expression of TIMP-1, endogenous inhibitor of MMP, was significantly increased by BJF. The expression of collagens I, III, IV was significantly decreased by BJF treatment (Figure 6).

3.4. Molecular Alterations at the Transcript, Protein, and Metabolite Levels. To illustrate the system-wide mechanism of long-term effect of BJF, we detected the transcriptomics, proteomics, and metabolomics profiling of lung tissues.

The microarray-based RNA expression analysis was performed. Of the 41000 genes profiled, 976 and 2857 exhibited significant alterations in COPD model rats (versus control) and BJF treatment rats (versus COPD model), respectively 

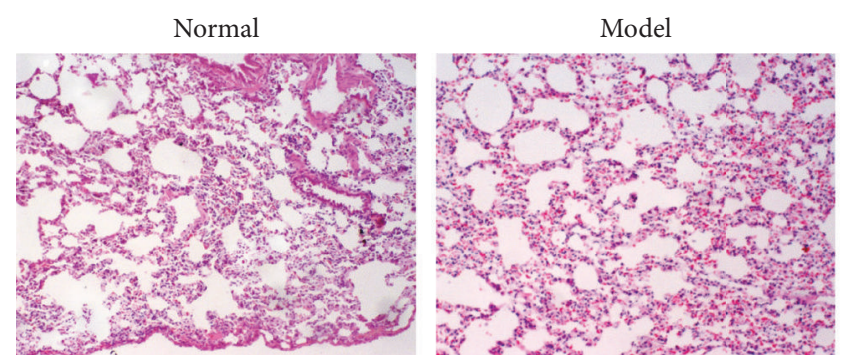
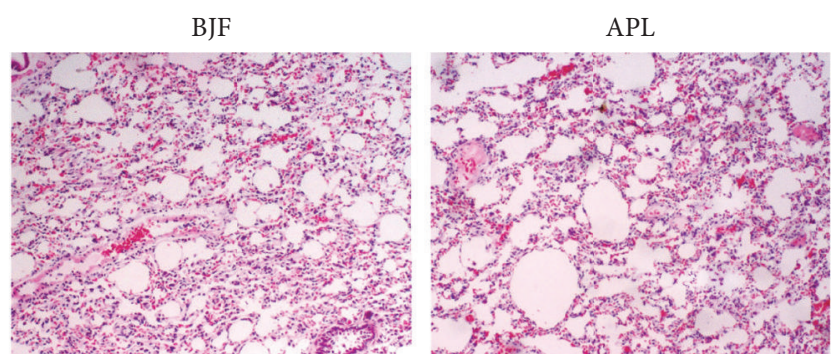

(a)

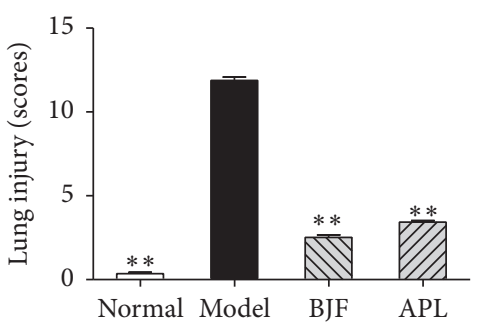

(b)

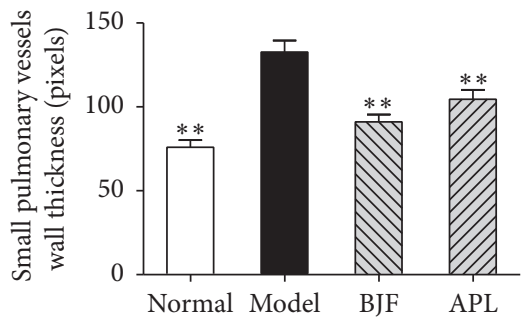

(e)

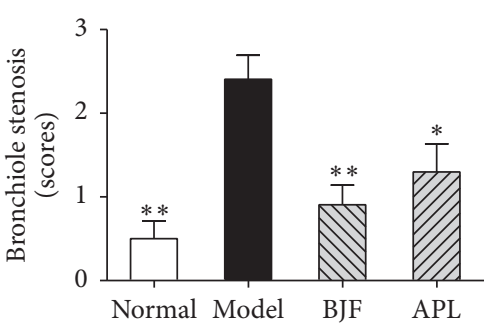

(c)

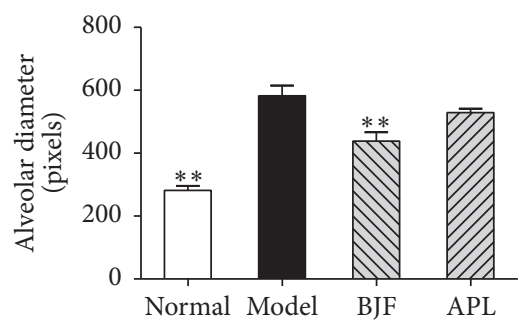

(f)

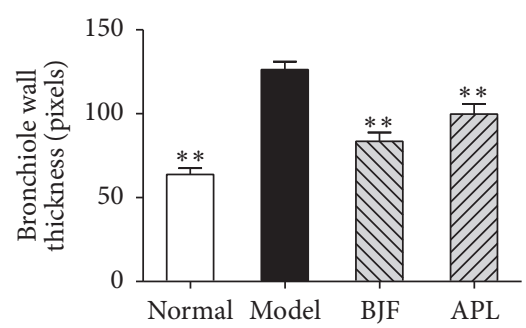

(d)

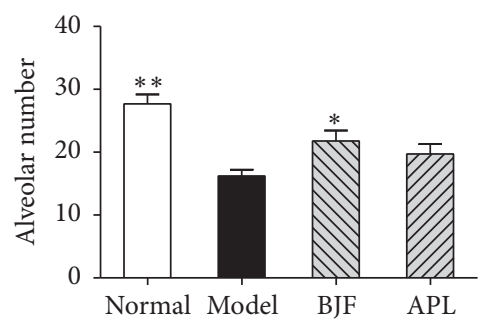

(g)

FIGURE 2: Effects of BJF on pathology changes in each experimental rat group. Histopathologic changes of the lung tissues were tested by hematoxylin and eosin staining on week 32 (magnification, $\times 100$ ) (a). The lung injury scores (b), bronchiole stenosis (c), bronchial wall thickness (d), small pulmonary vessels wall thickness (e), alveolar diameter (f), and alveolar number (g) were analyzed. Results were given as means \pm SEM, ${ }^{*} p<0.05$, and ${ }^{* *} p<0.01$ versus model.

(see Supplementary Tables A1 and A2 available online at https://doi.org/10.1155/2017/7091087). We found these genes were related to many biological functions, such as oxidoreductase, ion channel, or metalloendopeptidase activity (Figure 7). Then, we performed the gene set enrichment analysis and found many significantly altered pathways at mRNA expression level (Tables 1 and 2).

We then detected the protein expression profile of lung tissues. A total of 191 and 168 differentially expressed proteins were detected in model and BJF-treated rats (Supplementary Tables A3 and A4). These proteins were mainly involved in these biological functions, such as oxidoreductase activity, peroxiredoxin activity, and nitric-oxide synthase regulator activity (Figures 8(a) and 8(b)), and attributed to many different pathways, such as focal adhesion (Tables 3 and 4).

Furthermore, we observed the COPD model group (191 proteins) shared 127 proteins of the BJF-treated-group (168 proteins). Expression changes of 82 proteins (among the 127 proteins) in COPD model rats were suppressed by BJF (Supplementary Table A5). The 82 proteins were mainly related to these biological functions, including oxidoreductase, glutathione transferase, NAD or NADH binding, and eukaryotic cell surface binding activity (Figure 8(c)), which was probably relevant for the therapeutic action of BJF.

After metabolomics analysis, 41 and 68 differentially regulated metabolites were identified in model (versus control) and BJF-treated (versus model) rats, respectively (Supplementary Tables A6 and A7). MetaboAnalyst was applied to analyze metabolic pathway (Tables 5 and 6 ). We found many significantly altered pathways at the metabolomic level in COPD model and BJF-treated rats, involved in metabolism of arachidonic acid, linoleic acid, glutathione, or glycerophospholipid among others (Figure 9).

3.5. System Views on Genes, Proteins, and Metabolites Data. Here, many significantly regulated genes, proteins, and metabolites, related to the therapeutic effect of BJF, were identified. For further holistic analysis, the genes, proteins, and metabolites were integrated to provide a systems biological interpretation. 

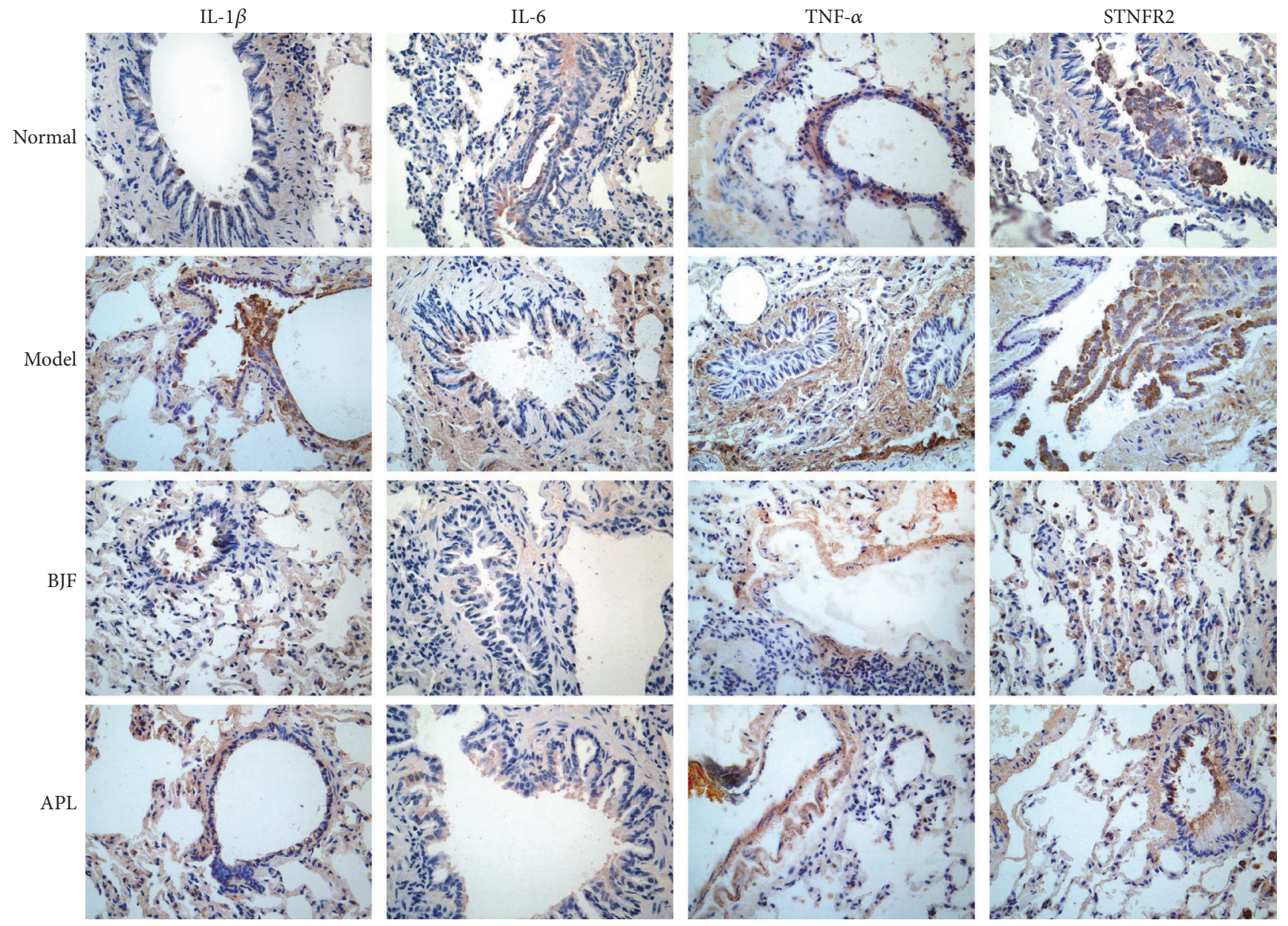

(a)
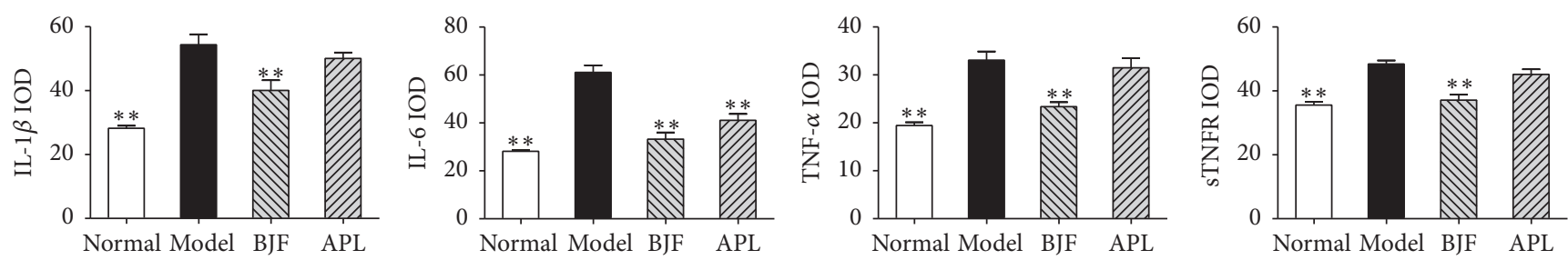

(b)

Figure 3: Effect of BJF on IL-1 $\beta$, IL-6 TNF- $\alpha$, and sTNFR2 expression in COPD rat lung tissue. IL-1 $\beta$, IL-6, TNF- $\alpha$, and sTNFR2 in lung tissues were detected with immunohistochemistry (magnification, $\times 100$ ) on week 32 (a). Quantitative analysis for IL-6, IL-1 $\beta$, TNF- $\alpha$, and sTNFR2 expression was performed (b). Results were given as means \pm SEM and ${ }^{* *} p<0.01$ versus model.

We firstly built the gene-metabolite networks based on the transcriptomics and metabolomics data of model and BJF-treated rats. We observed these genes and metabolites were primarily involved in lipid, purine, or energy metabolism (Figures 10(a) and 10(b)). Similarly, we constructed metabolite-protein networks, which contained three main parts: lipid metabolism, purine metabolism, or glutathione metabolism (Figures 10(c) and 10(d)). These results suggested that lipid metabolism played an important role in COPD progression and long-term anti-COPD effect of BJF.
3.6. Integration of System Pharmacology, Transcriptomics, Proteomics, and Metabolomics Data. We previously identified 175 targets of the BJF using system pharmacology methods (Supplementary Table A8) and examined the short-term anti-COPD of BJF. Now, the above data indicated that BJF has long-term efficiency for the treatment of COPD rats. Next, we sought to illustrate the system mechanism of the long-term anti-COPD effect of BJF by combining the transcriptomics, proteomics, and metabolomics and system pharmacology data. 


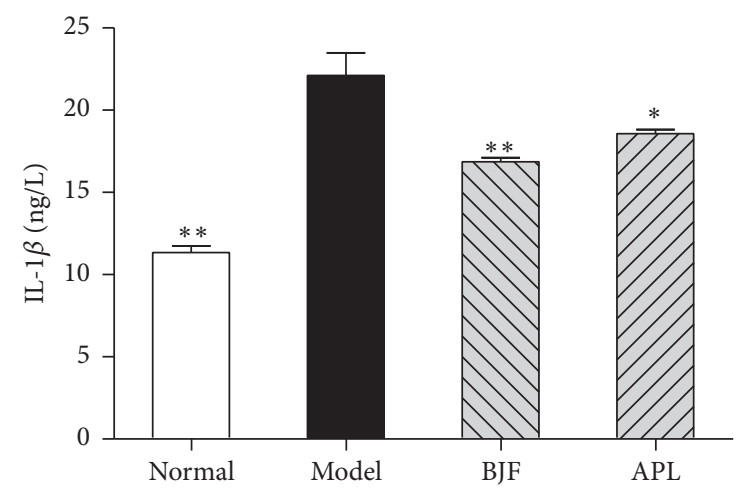

(a)

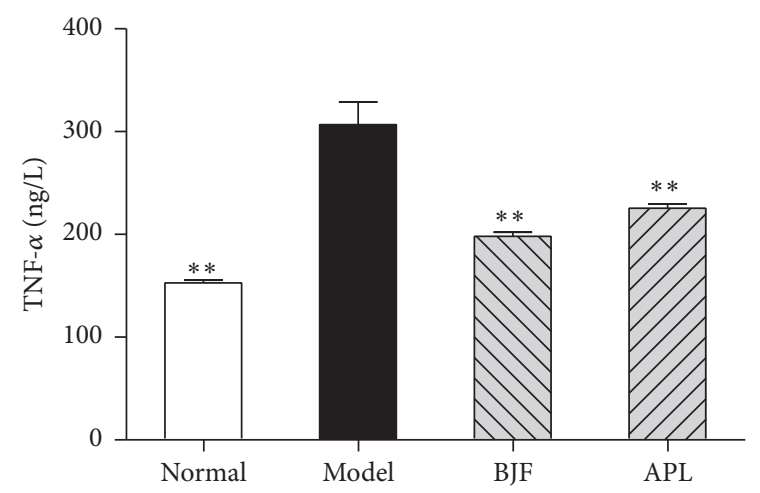

(c)

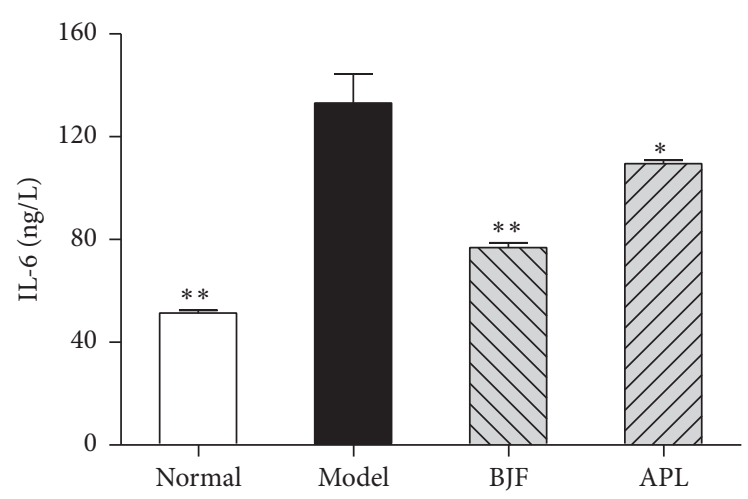

(b)

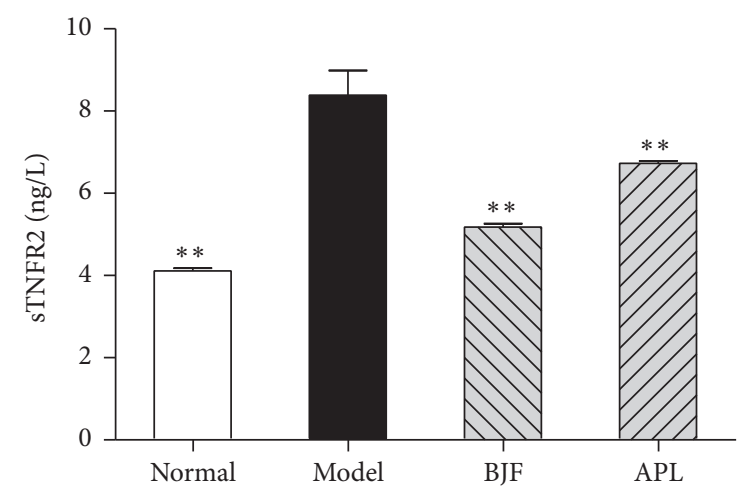

(d)

FIGURE 4: Effect of BJF on IL-1 $\beta$, IL-6 TNF- $\alpha$, and sTNFR2 expression in serum of COPD rats. IL-1 $\beta$ (a), IL-6 (b), TNF- $\alpha$ (c), and sTNFR2 (d) in serum were detected on week 32 . Results were given as means \pm SEM, ${ }^{*} p<0.05$, and ${ }^{* *} p<0.01$ versus model.

Initially we explored the biological functions of the overlapping proteins between potential targets of BJF and transcripts in BJF-treated rats. The result showed that 11 overlapping proteins (ACACA, ampC, APP, BCL2, CDK2, FASN, gyrB, katA, KCNH2, MAPK3, and NR3C1) were related to many different biological functions including oxidoreductase activity, MAP kinase activity, and NF-kappa-B binding (Figure 11(a)). Next, 9 overlapping proteins (ATP5B, CALM1, COL1A1, HBB, HSPA5, MGC72973, SOD1, LOC100134871, and LOC689064) between the system pharmacology targets and proteins regulated in BJF-treated rats were identified. The molecular functions of the 9 proteins were mainly related to oxidoreductase, antioxidant, superoxide dismutase activity, and ATPase activity (Figure 11(b)). Furthermore, the potential relationships of target proteins and metabolites regulated in BJF-treated rats were analyzed. In Figure 12, the results showed that metabolite-target protein network mainly contained lipid metabolism.

Finally, we constructed a system picture of the molecular mechanisms of long-term anti-COPD effect of BJF based on above comprehensive data. As shown in Figure 13, the comprehensive picture consisted of four parts: lipid metabolism, inflammatory response, oxidative stress, and focal adhesion pathway.
In lipid metabolism analysis, BJF decreased the levels of metabolites, such as lecithin, arachidonate, PGE2, LTB4, and 11-epi-PGF2 $\alpha$. We also found these metabolites, including arachidonate, PGE2, and LTB4, elevated in the airways of COPD patients [23-25]. In addition, the critical metabolic enzymes including PTGS1/2, LTA4H, ALOX5, AKR1C3, and CYP1A2/4 were the system pharmacology targets of BJF. Furthermore, the system pharmacology study demonstrated that MAPK1/3 (ERK1/2), MAPK14 (p38), MAPK8 (JNK), and NF- $\kappa$ B were the predicted targets of BJF. We also found that BJF treatment could sustainably decrease the level of IL-1 $\beta$, IL-6 TNF- $\alpha$, and sTNFR2 in lung tissues and serum of COPD rats.

The oxidative stress continuously generates reactive oxygen species, causes lipid peroxidation, and further leads to sustained inflammatory responses, which is a major contributing factor to obstructive disorders in lungs [26-28]. Glutathione (GSH) is one of the main antioxidants, which can provide antioxidant defenses by their ability to exist in reversible oxidized and reduced forms $[29,30]$. In addition, the lung has also reliance on superoxide dismutase, catalase, glutathione peroxidase, and glutathione-S-transferase as they are important enzymatic antioxidants of the lungs. Here, we identified the metabolites (5-oxoproline, L-ornithine), transcripts (GSTM4), proteins (GSTA4), and potential targets 

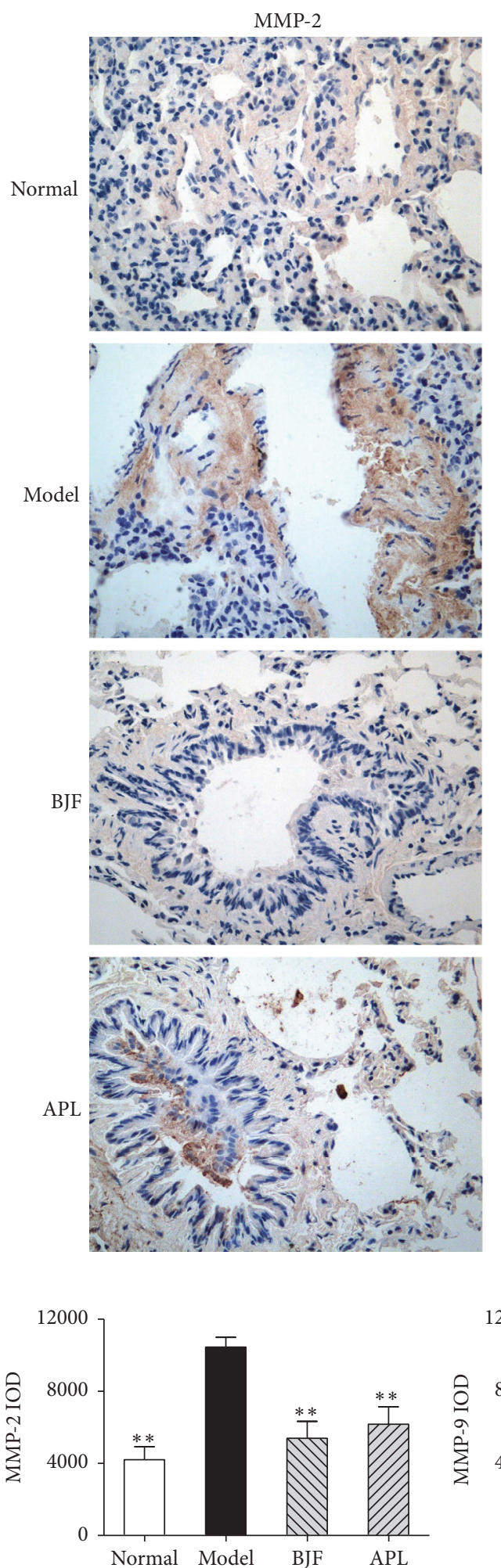
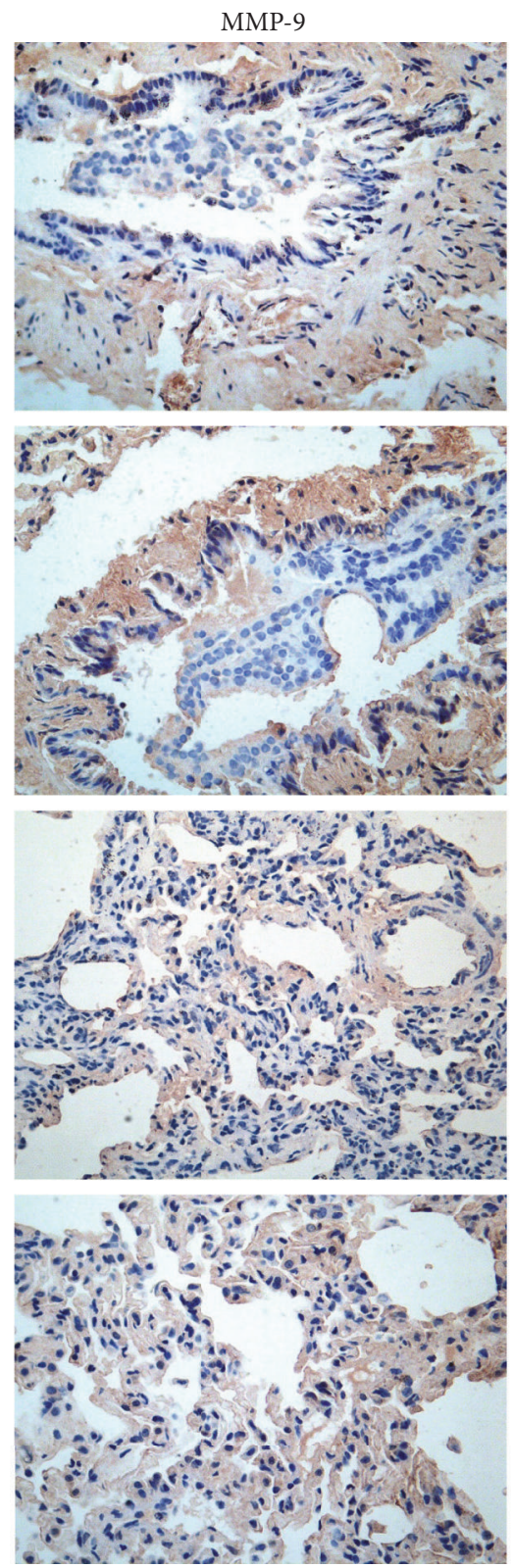

(a)

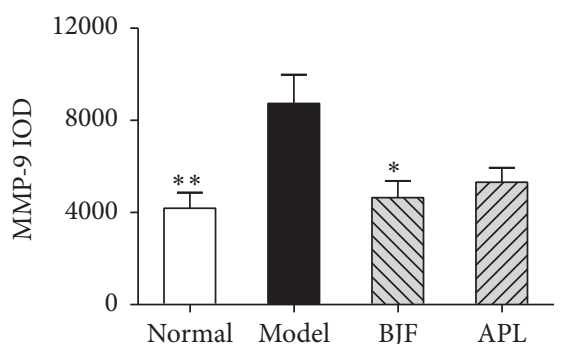

(b)
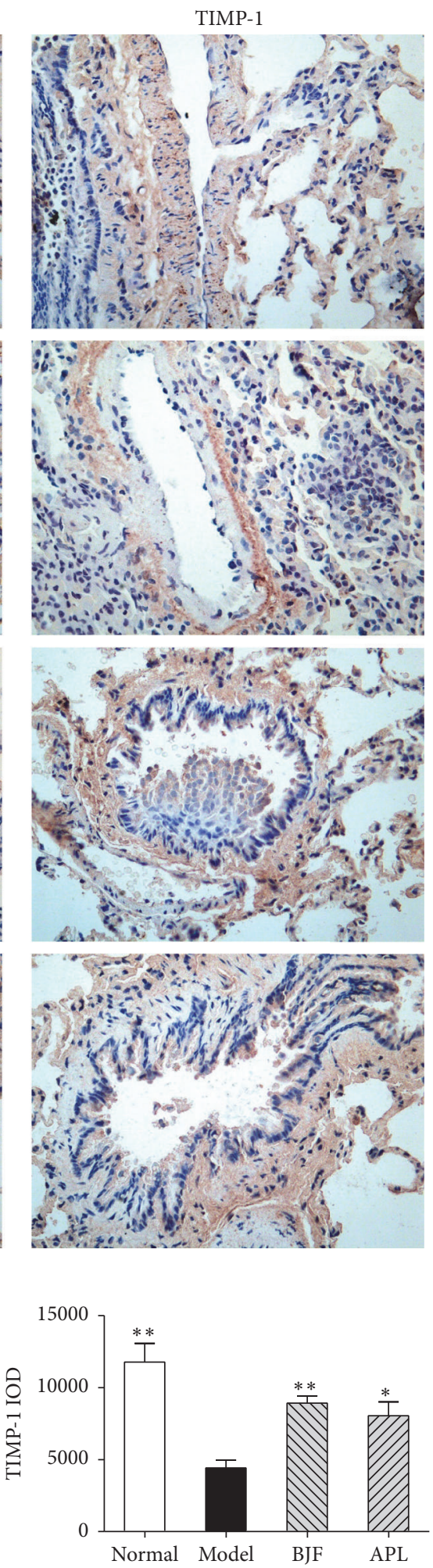

FIGURE 5: Effect of BJF on MMP-2, MMP-9, and TIMP-1 expression in the COPD rat lung tissue. Immunohistochemical analysis for MMP-2, MMP-9, and TIMP-1 expression in the lung tissues was performed on week 32 (magnification, $\times 100$ ) (a). Quantitative analysis expression level of MMP-2, MMP-9, and TIMP-1 was quantified based on the immunohistochemical testing (b). Values represent means \pm SEM and $n=10 .{ }^{*} p<0.05$ and $^{* *} p<0.01$ versus model. 

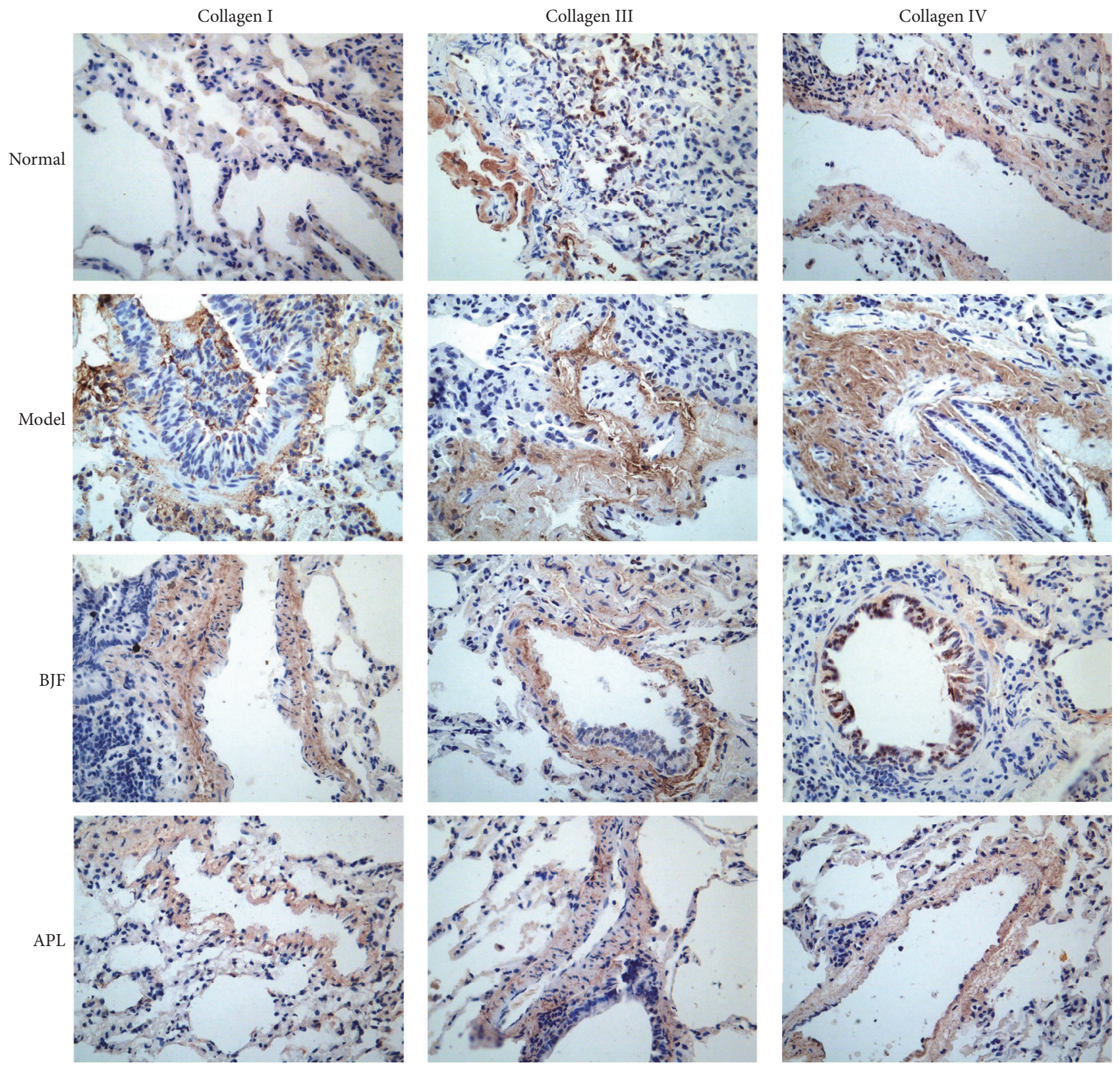

(a)
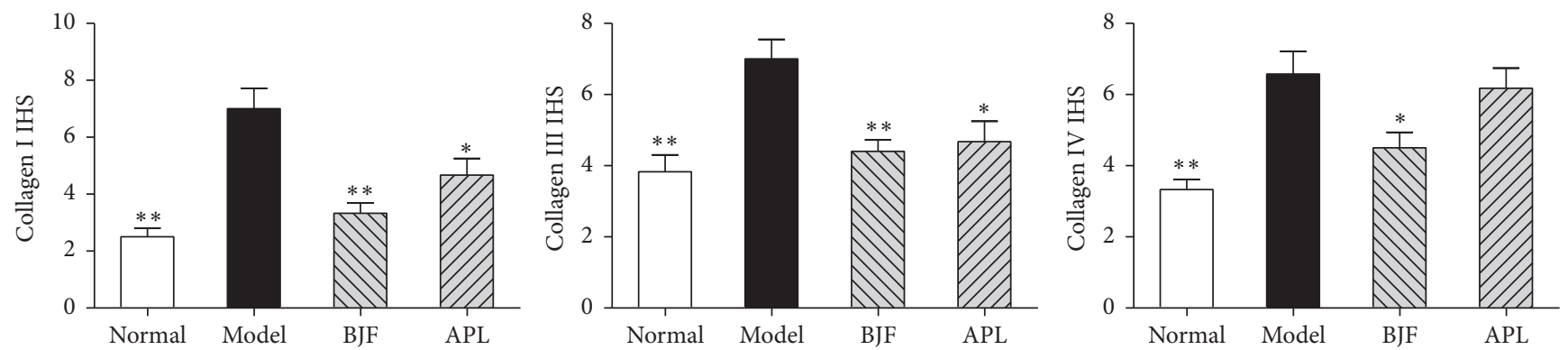

(b)

FIGURE 6: Effect of BJF on expression of collagens I, III, and IV in COPD rat lung tissues. The expression of collagens I, III, and IV was analyzed by immunohistochemistry (magnification, $\times 100$ ) on week 32 (a). The expression levels of collagens I, III, and IV were quantitatively analyzed (b). Values represent means \pm SEM. ${ }^{*} p<0.05$ and ${ }^{* *} p<0.01$ versus model. 


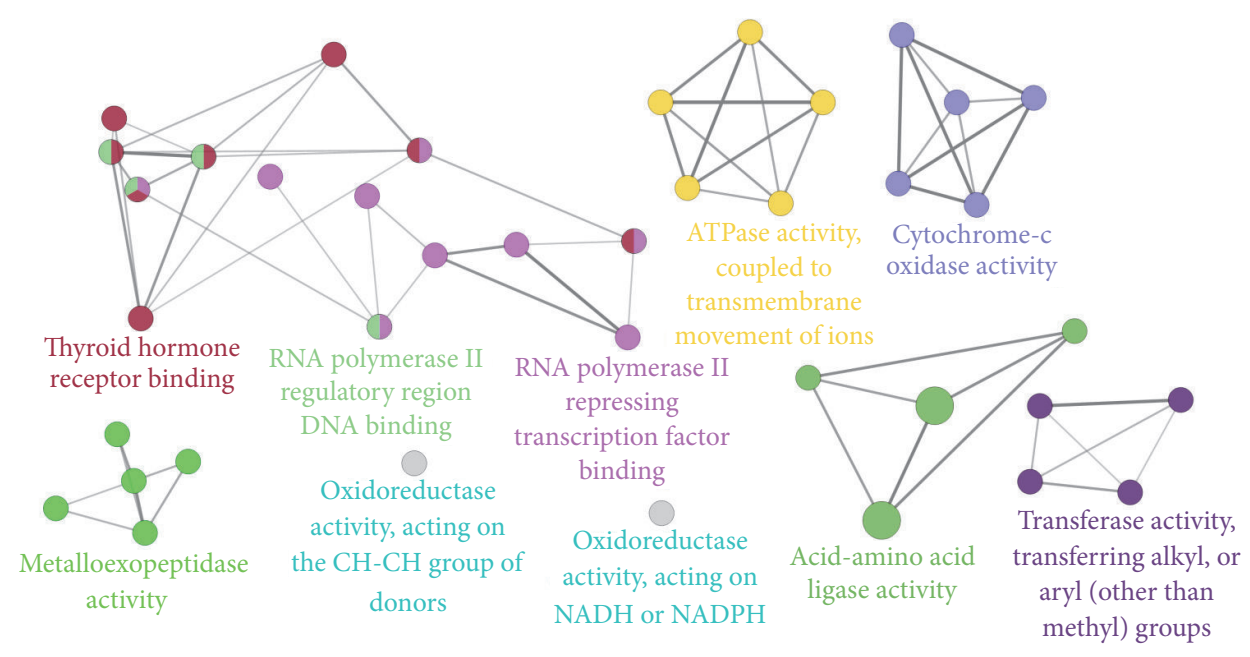

(a)

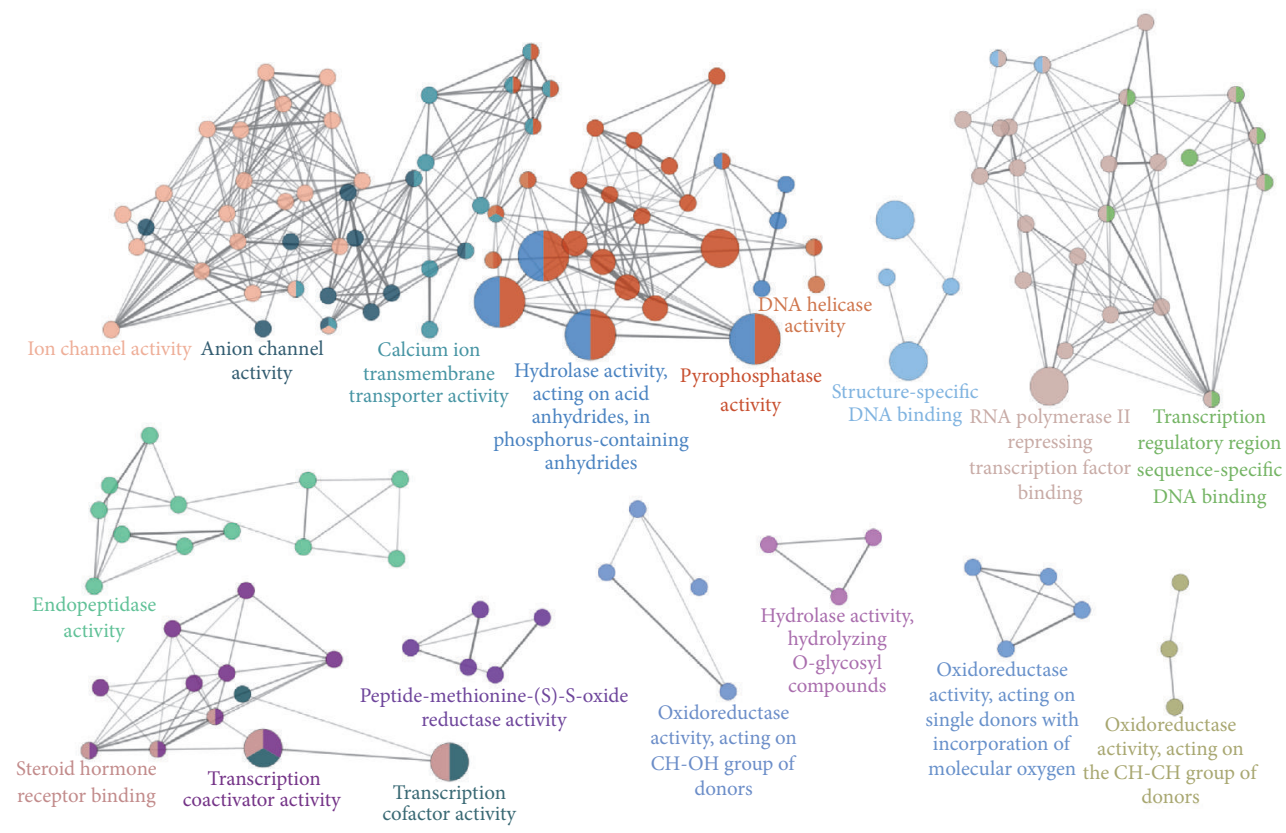

(b)

FIGURE 7: ClueGO analysis of molecular functions of regulated genes in COPD rat and BJF-treated rat lung tissues. (a) The molecular functions of regulated genes in COPD rats. (b) The molecular functions of regulated genes in BJF-treated rats. Functionally grouped network of enriched categories was generated for the regulated genes.

(GSR, GSTP1, GSTM1/2), which were mainly related to glutathione metabolism. We also found that the antioxidant proteins including SOD1 (superoxide dismutase) and KatA (catalase) were increased by BJF treatment (Supplementary Tables A2, A4). For correlation analyses on pathway levels, significant pathways from proteomic and potential targets data were integrated. We found focal adhesion was one of the significant deregulated pathways (Tables 3 and 4), and the activation of MAPK1/3, 8 , and JUN could increase preinflammatory cytokines expression. Above results implied that BJF achieved its anti-inflammatory activity probably by modulating lipid metabolism, the preinflammatory cytokines production, and their corresponding pathways activation, the metabolism of glutathione, and the expression level of antioxidants.

In summary, these data suggested that BJF showed the long-term anti-COPD therapeutic effect on rats through modulating system biological functions, including lipid 
TABLE 1: Related pathways of transcriptomics detected in COPD rat lung tissue.

\begin{tabular}{lccc}
\hline Term & Count & $\%$ & $p$ value \\
\hline Ribosome & 16 & 0.2530 & 0.0000 \\
Ubiquitin mediated & 12 & 0.1898 & \\
proteolysis & & 0.1740 & 0.0008 \\
Neurotrophin signaling & 11 & 0.1582 & 0.027 \\
pathway & 10 & 0.1107 & 0.0067 \\
Spliceosome & 7 & 0.1582 & 0.0108 \\
Long-term potentiation & 10 & 0.0949 & 0.0145 \\
Oxidative phosphorylation & 6 & 0.0949 & 0.0147 \\
Non-small cell lung cancer & 6 & 0.1423 & 0.0437 \\
Renal cell carcinoma & 9 & 0.1740 & 0.0457 \\
Parkinson's disease & 11 & 0.1107 & 0.0469 \\
Focal adhesion & 7 & 0.1740 & 0.0480 \\
GnRH signaling pathway & 11 & 0.0497 \\
Alzheimer's disease & & & \\
\hline
\end{tabular}

TABLE 2: Related pathways of transcriptomics detected in BJF-treated rats lung tissue.

\begin{tabular}{|c|c|c|c|}
\hline Term & Count & $\%$ & $p$ value \\
\hline Ribosome & 29 & 0.174751 & $6.30 E-12$ \\
\hline $\begin{array}{l}\text { Aminoacyl-tRNA } \\
\text { biosynthesis }\end{array}$ & 11 & 0.066285 & $7.15 E-04$ \\
\hline Endocytosis & 30 & 0.180777 & $7.19 E-04$ \\
\hline Prostate cancer & 17 & 0.10244 & 0.001294 \\
\hline Renal cell carcinoma & 14 & 0.084363 & 0.002109 \\
\hline $\begin{array}{l}\text { Ubiquitin mediated } \\
\text { proteolysis }\end{array}$ & 20 & 0.120518 & 0.00352 \\
\hline $\begin{array}{l}\text { Neurotrophin signaling } \\
\text { pathway }\end{array}$ & 20 & 0.120518 & 0.00352 \\
\hline Adherens junction & 14 & 0.084363 & 0.004004 \\
\hline Tight junction & 20 & 0.120518 & 0.005003 \\
\hline Citrate cycle (TCA cycle) & 8 & 0.048207 & 0.006777 \\
\hline $\begin{array}{l}\text { MAPK signaling } \\
\text { pathway }\end{array}$ & 32 & 0.192829 & 0.013297 \\
\hline Proteasome & 10 & 0.060259 & 0.013316 \\
\hline $\begin{array}{l}\text { Nucleotide excision } \\
\text { repair }\end{array}$ & 9 & 0.054233 & 0.015824 \\
\hline $\mathrm{N}$-Glycan biosynthesis & 9 & 0.054233 & 0.018075 \\
\hline Spliceosome & 17 & 0.10244 & 0.023539 \\
\hline $\begin{array}{l}\text { Oxidative } \\
\text { phosphorylation }\end{array}$ & 18 & 0.108466 & 0.03465 \\
\hline $\begin{array}{l}\text { Antigen processing and } \\
\text { presentation }\end{array}$ & 13 & 0.078337 & 0.037581 \\
\hline Propanoate metabolism & 7 & 0.042181 & 0.038533 \\
\hline Endometrial cancer & 9 & 0.054233 & 0.040556 \\
\hline $\begin{array}{l}\text { Amino sugar and } \\
\text { nucleotide sugar } \\
\text { metabolism }\end{array}$ & 8 & 0.048207 & 0.045144 \\
\hline
\end{tabular}




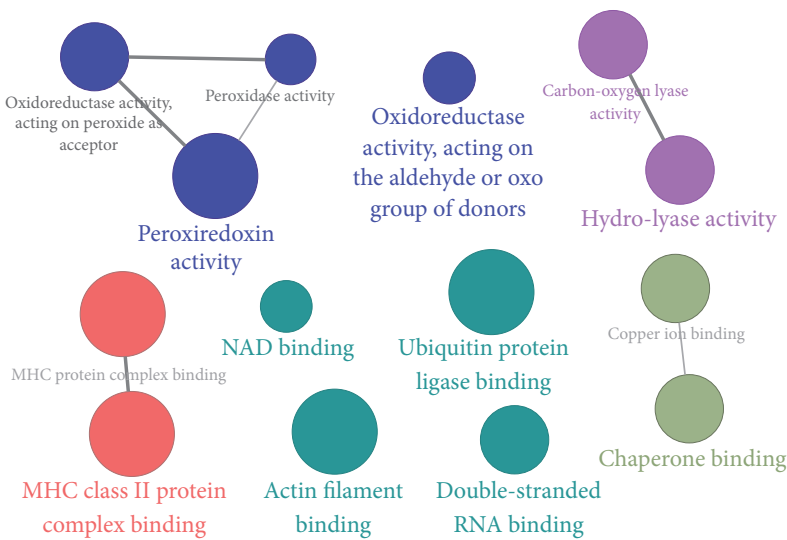

(a)

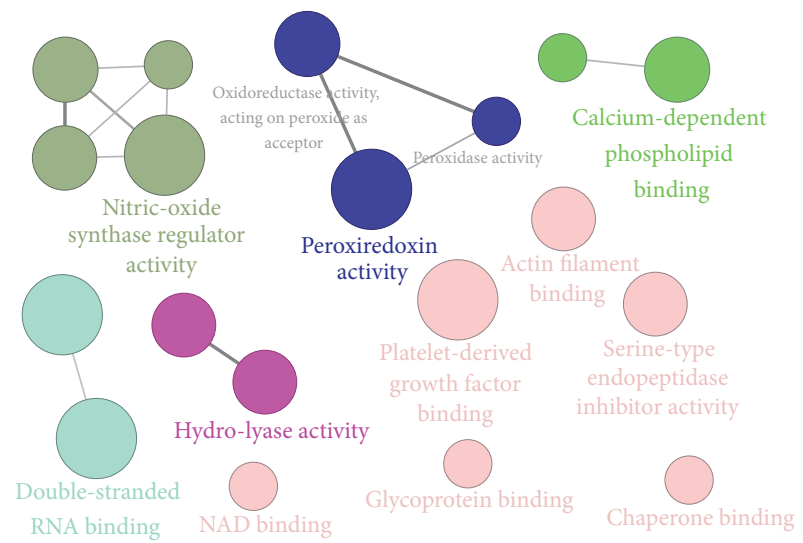

(b)

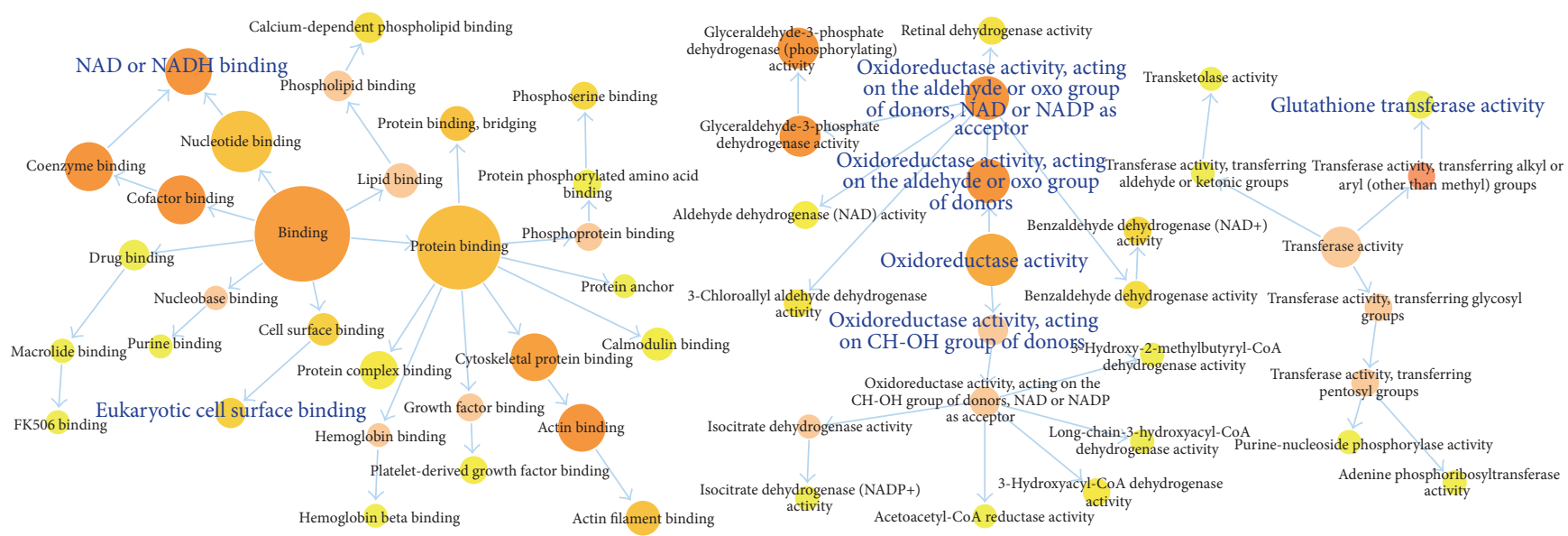

(c)

FIGURE 8: Molecular functions of regulated proteins in COPD rat and BJF-treated rat lung tissues. (a) The molecular functions of regulated proteins in COPD rats, (b) the molecular functions of regulated proteins in BJF-treated rats, and (c) the molecular function of the 127 overlapping proteins.

TABLE 3: Related pathways of proteins identified in COPD rats lung tissue.

\begin{tabular}{lccc}
\hline Term & Count & $\%$ & $p$ value \\
\hline ECM-receptor interaction & 8 & 0.3666 & 0.0002 \\
Focal adhesion & 11 & 0.5041 & 0.0006 \\
Leukocyte transendothelial migration & 7 & 0.3208 & 0.0069 \\
Glycolysis/gluconeogenesis & 6 & 0.2750 & 0.0079 \\
Propanoate metabolism & 4 & 0.1833 & 0.0125 \\
Pyruvate metabolism & 4 & 0.1833 & 0.0196 \\
Tryptophan metabolism & 4 & 0.1833 & 0.0254 \\
Valine, leucine, and isoleucine & 4 & 0.1833 & 0.0303 \\
degradation & 4 & 0.2291 & 0.0343 \\
Small cell lung cancer & 5 & 0.3666 & 0.0348 \\
Regulation of actin cytoskeleton & 8 & 0.2750 & 0.0433 \\
Tight junction & 6 & 0.1375 & 0.0450 \\
Nitrogen metabolism & 3 & 0.1375 & 0.0487 \\
Pentose phosphate pathway & 3 & & \\
\hline
\end{tabular}


TABLE 4: Related pathways of proteins identified in BJF-treated rats lung tissue.

\begin{tabular}{lccc}
\hline Term & Count & $\%$ & $p$ value \\
\hline $\begin{array}{l}\text { ECM-receptor } \\
\text { interaction }\end{array}$ & 9 & 5.882353 & $1.71 E-05$ \\
$\begin{array}{l}\text { Focal adhesion } \\
\begin{array}{l}\text { Leukocyte } \\
\text { transendothelial } \\
\text { migration }\end{array}\end{array}$ & 13 & 8.496732 & $1.74 E-05$ \\
$\begin{array}{l}\text { Regulation of actin } \\
\text { cytoskeleton }\end{array}$ & 7 & 4.575163 & 0.005802 \\
$\begin{array}{l}\text { Huntington's } \\
\text { disease }\end{array}$ & 9 & 5.882353 & 0.00959 \\
$\begin{array}{l}\text { Valine, leucine, } \\
\text { and isoleucine } \\
\text { degradation }\end{array}$ & 8 & 5.228758 & 0.018396 \\
$\begin{array}{l}\text { Neurotrophin } \\
\text { signaling pathway }\end{array}$ & 4 & 2.614379 & 0.02757 \\
\begin{tabular}{l} 
Tight junction \\
\hline
\end{tabular} & 6 & 3.921569 & 0.03371 \\
\end{tabular}

TABLE 5: Related pathways of metabolites identified in COPD rat lung tissue.

\begin{tabular}{|c|c|c|c|c|}
\hline Term & Total & Expected & Hits & Raw $p$ \\
\hline $\begin{array}{l}\text { Biosynthesis of } \\
\text { unsaturated fatty } \\
\text { acids }\end{array}$ & 42 & 0.6591 & 6 & $2.62 E-05$ \\
\hline $\begin{array}{l}\text { Arachidonic acid } \\
\text { metabolism }\end{array}$ & 36 & 0.5649 & 4 & 0.001929 \\
\hline $\begin{array}{l}\text { Linoleic acid } \\
\text { metabolism }\end{array}$ & 5 & 0.0785 & 2 & 0.002286 \\
\hline $\begin{array}{l}\text { Sphingolipid } \\
\text { metabolism }\end{array}$ & 21 & 0.3295 & 3 & 0.003718 \\
\hline $\begin{array}{l}\text { Glycerophospholipid } \\
\text { metabolism }\end{array}$ & 30 & 0.4708 & 3 & 0.010353 \\
\hline $\begin{array}{l}\text { Cyanoamino acid } \\
\text { metabolism }\end{array}$ & 6 & 0.0942 & 1 & 0.09069 \\
\hline $\begin{array}{l}\text { alpha-Linolenic acid } \\
\text { metabolism }\end{array}$ & 9 & 0.1412 & 1 & 0.13304 \\
\hline Methane metabolism & 9 & 0.1412 & 1 & 0.13304 \\
\hline $\begin{array}{l}\text { Fatty acid } \\
\text { biosynthesis }\end{array}$ & 43 & 0.6748 & 2 & 0.1443 \\
\hline $\begin{array}{l}\text { Steroid hormone } \\
\text { biosynthesis }\end{array}$ & 70 & 1.0984 & 2 & 0.3014 \\
\hline $\begin{array}{l}\text { Cysteine and } \\
\text { methionine } \\
\text { metabolism }\end{array}$ & 28 & 0.4394 & 1 & 0.36059 \\
\hline $\begin{array}{l}\text { Glycine, serine, and } \\
\text { threonine metabolism }\end{array}$ & 32 & 0.5021 & 1 & 0.40061 \\
\hline Steroid biosynthesis & 35 & 0.5492 & 1 & 0.42905 \\
\hline $\begin{array}{l}\text { Primary bile acid } \\
\text { biosynthesis }\end{array}$ & 46 & 0.7218 & 1 & 0.52269 \\
\hline $\begin{array}{l}\text { Aminoacyl-tRNA } \\
\text { biosynthesis }\end{array}$ & 67 & 1.0514 & 1 & 0.66232 \\
\hline
\end{tabular}


TABLE 6: Related pathways of metabolites identified in BJF-treated rat lung tissue.

\begin{tabular}{|c|c|c|c|c|}
\hline Term & Total & Expected & Hits & Raw $p$ \\
\hline $\begin{array}{l}\text { Arachidonic acid } \\
\text { metabolism }\end{array}$ & 36 & 0.8217 & 7 & $8.52 E-06$ \\
\hline $\begin{array}{l}\text { Biosynthesis of } \\
\text { unsaturated fatty acids }\end{array}$ & 42 & 0.9586 & 5 & 0.002093 \\
\hline Linoleic acid metabolism & 5 & 0.1141 & 2 & 0.004837 \\
\hline $\begin{array}{l}\text { Glycerophospholipid } \\
\text { metabolism }\end{array}$ & 30 & 0.6847 & 3 & 0.028867 \\
\hline Glutathione metabolism & 26 & 0.5934 & 2 & 0.11684 \\
\hline $\begin{array}{l}\text { alpha-Linolenic acid } \\
\text { metabolism }\end{array}$ & 9 & 0.2054 & 1 & 0.18812 \\
\hline Fatty acid biosynthesis & 43 & 0.9815 & 2 & 0.25705 \\
\hline $\begin{array}{l}\text { Selenoamino acid } \\
\text { metabolism }\end{array}$ & 15 & 0.3424 & 1 & 0.29397 \\
\hline Histidine metabolism & 15 & 0.3424 & 1 & 0.29397 \\
\hline Butanoate metabolism & 20 & 0.4565 & 1 & 0.37185 \\
\hline $\begin{array}{l}\text { Sphingolipid } \\
\text { metabolism }\end{array}$ & 21 & 0.4793 & 1 & 0.38639 \\
\hline $\begin{array}{l}\text { Alanine, aspartate, and } \\
\text { glutamate metabolism }\end{array}$ & 24 & 0.5478 & 1 & 0.4281 \\
\hline Pyrimidine metabolism & 41 & 0.9358 & 1 & 0.61733 \\
\hline $\begin{array}{l}\text { Arginine and proline } \\
\text { metabolism }\end{array}$ & 44 & 1.0043 & 1 & 0.64371 \\
\hline $\begin{array}{l}\text { Aminoacyl-tRNA } \\
\text { biosynthesis }\end{array}$ & 67 & 1.5292 & 1 & 0.79506 \\
\hline Purine metabolism & 68 & 1.5521 & 1 & 0.79997 \\
\hline
\end{tabular}

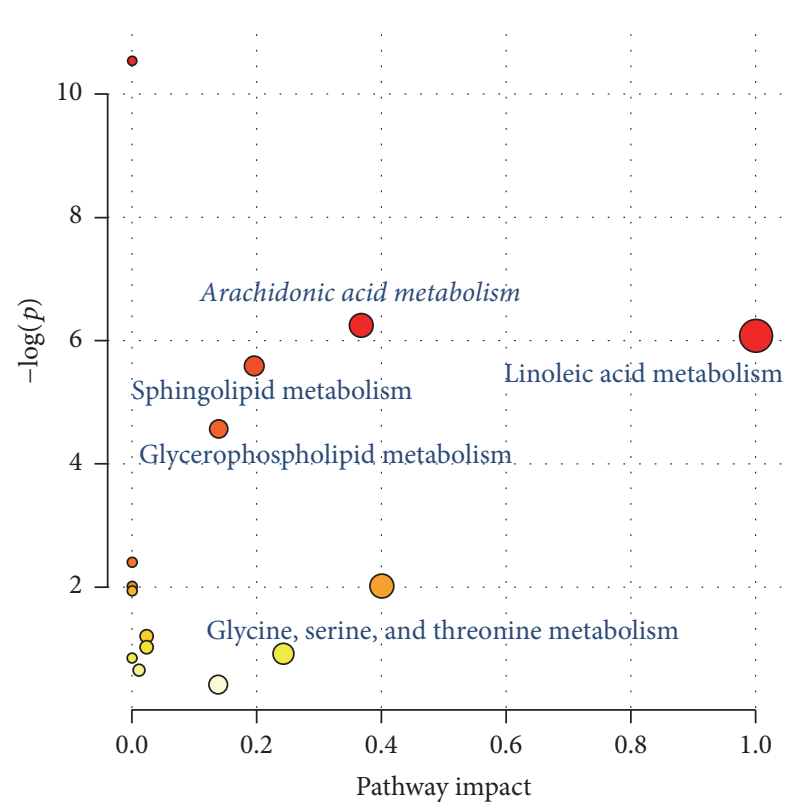

(a)

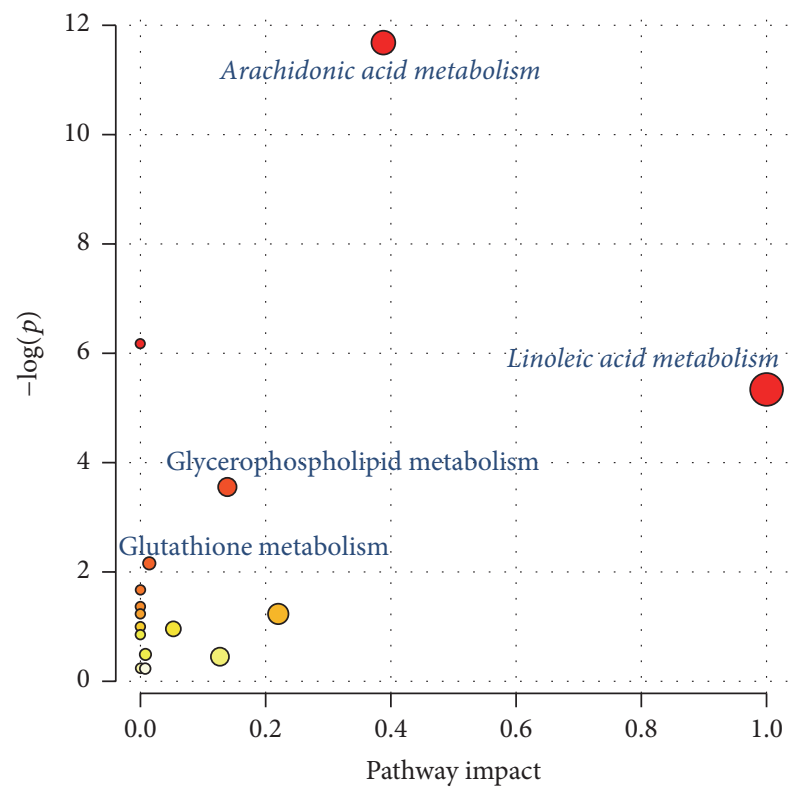

(b)

FIGURE 9: Pathway enrichment of the metabolites regulated in COPD rat and BJF-treated rat lung tissues. (a) Related pathway of the metabolites in COPD rat lung tissues. (b) Related pathway of the metabolites in BJF-treated rat lung tissues. 


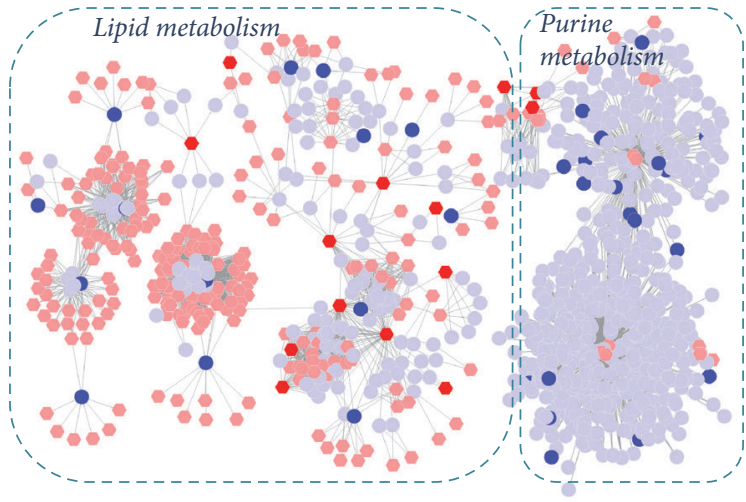

(a)

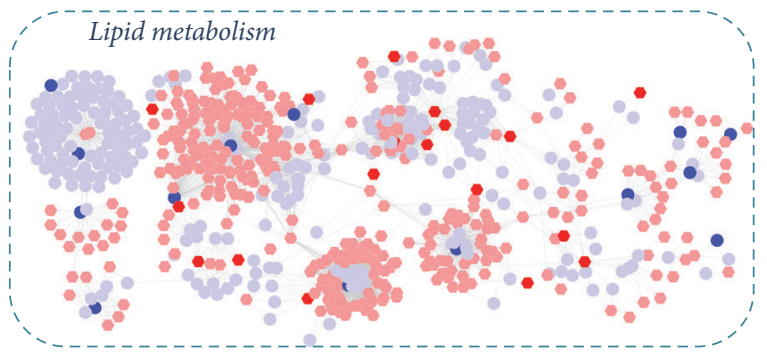

(c)

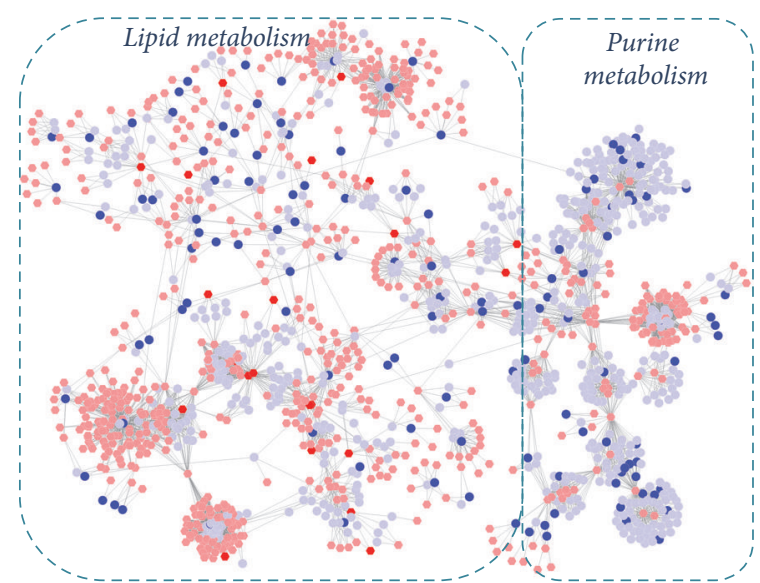

(b)

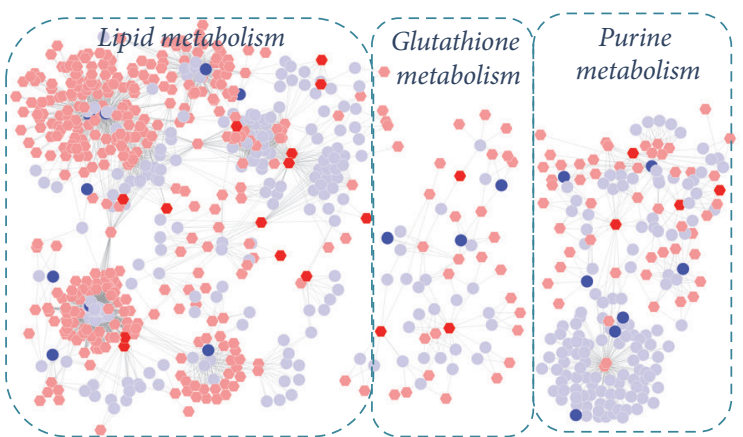

(d)

FIGURE 10: Correlation analysis of genes, proteins, and metabolites regulated in COPD rat and BJF-treated rat lung tissues. Metabolites-gene network analysis of COPD model (a) and BJF-treated group (b). Metabolites-protein network analysis of COPD model (c) and BJF-treated group (d). Networks of the metabolites, genes, and proteins were visualized by Metscape (hexagon node: compounds, round node: metabolic enzymes, and edge: reactions. Red: inputted genes and proteins; blue: inputted compounds).

metabolism, inflammatory response, oxidative stress, and focal adhesion pathway.

\section{Discussion}

Combining transcriptomics, proteomics, and metabolomics approaches is becoming more important in investigating the mechanisms of the therapeutic effect of Chinese herbal medicine and will most likely change the way we approach investigations of complex disease development. However, attempts thus far to integrate 3-omics data have been met with limited success. In this study, a system level approach based on integrating transcriptomics, proteomics, metabolomics, and system pharmacology data analysis was applied to clarify the long-term anti-COPD effect and its system mechanism of BJF. We administrated COPD rats with BJF during weeks 9 to 20 and then found BJF had long-term anti-COPD effect and could effectively inhibit the inflammatory cytokine expression, protease-antiprotease imbalance, and the collagen deposition on week 32. The transcriptomics, proteomics, and metabolomics profiles model and BJF-treated rats were further characterized, which could help us to dissect the long-term therapeutic mechanism of BJF at system level. The results showed that the regulated transcripts, proteins, and metabolites were related to many different biological functions, including oxidoreductase activity, antioxidant activity, and lipid metabolism. Furthermore, the comprehensive analysis results suggested that BJF showed its long-term antiCOPD effect probably through modulating lipid metabolism, inflammatory response, oxidative stress, and focal adhesion pathways. Taken together, an integrated transcriptomics, proteomics, and metabolomics approach combined with system pharmacology has the potential to considerably advance our understanding of the system mechanism of long-term therapeutic effect of traditional Chinese medicine. However, the main limitation of this work is its direct demand for further experimental validation such as the significant regulated genes, proteins, and metabolites in COPD and BJF-treated rats, which will be resolved in the follow-up works.

\section{Conflicts of Interest}

The authors declare that they have no competing interests. 

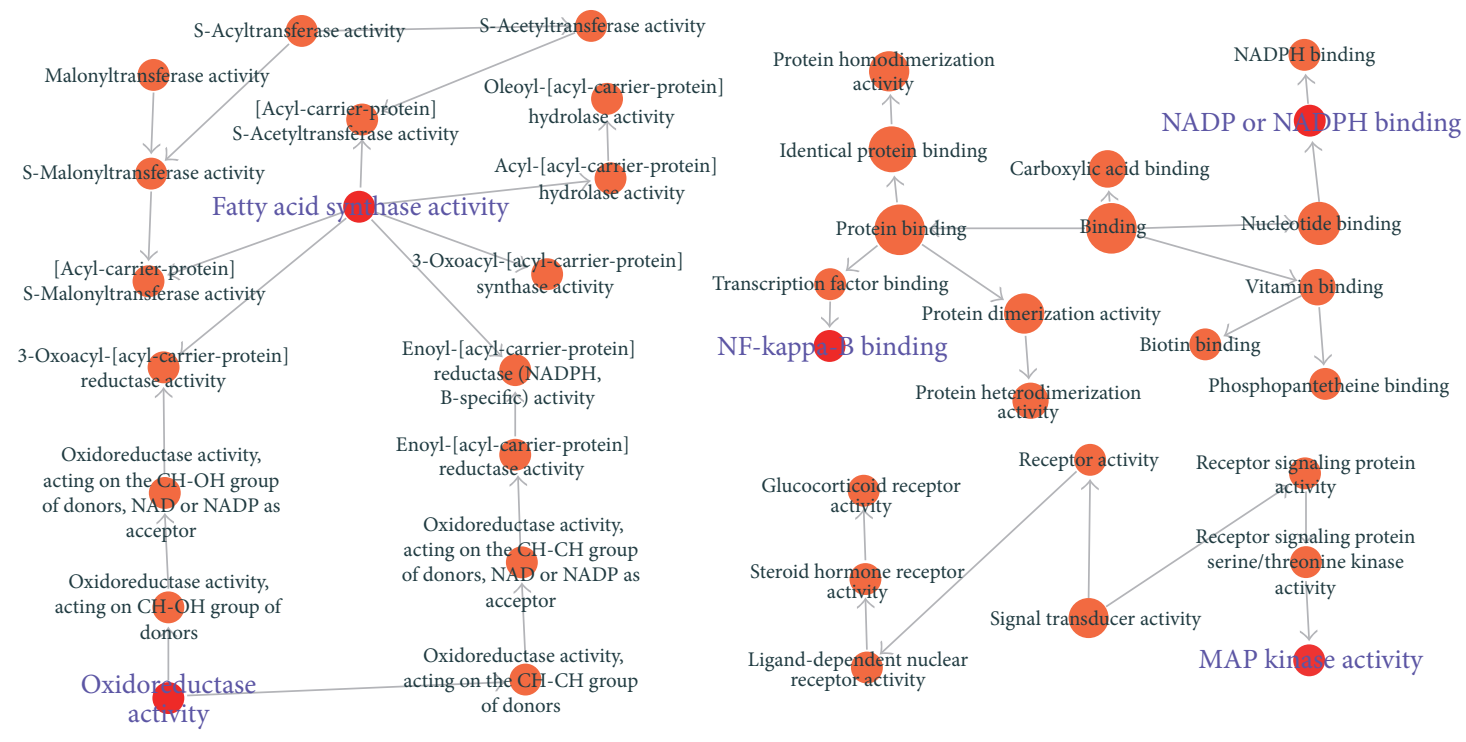

(a)

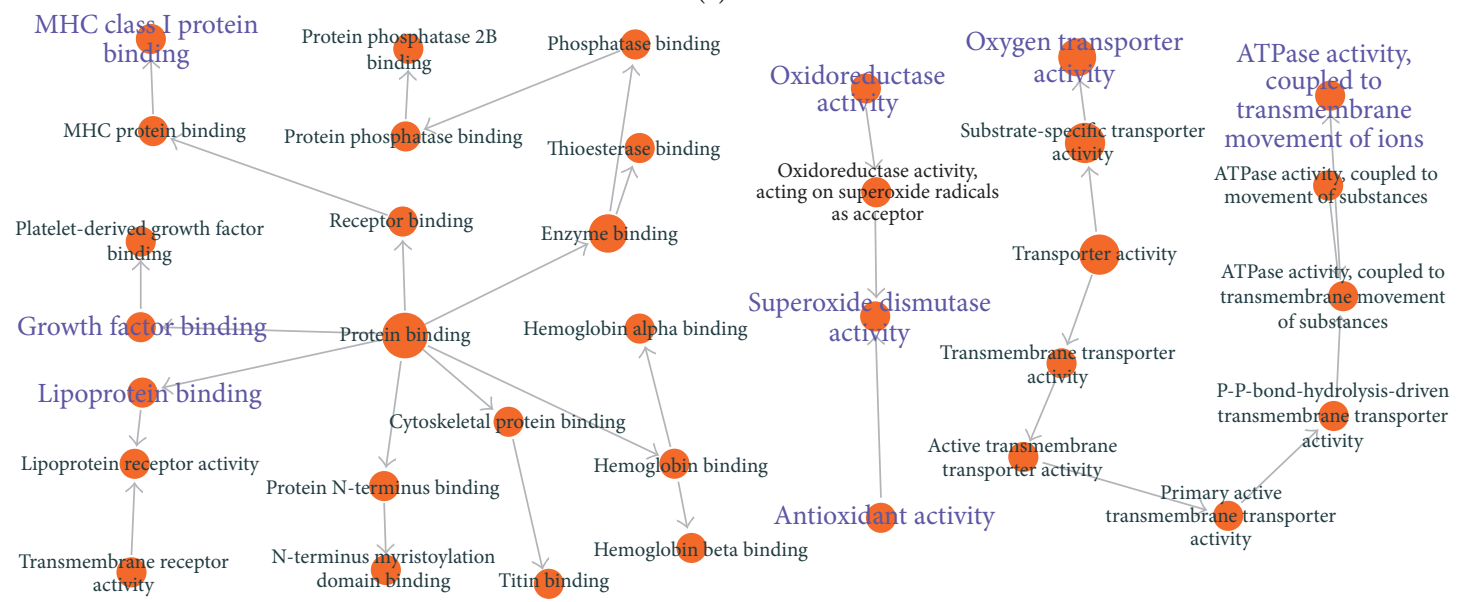

(b)

FIGURE 11: Overlapping proteins' molecular functions. BiNGO was applied to analyze the molecular functions of the overlapping proteins. (a) Molecular function analysis of overlapping proteins between the system pharmacology targets and transcript measurements in lung tissues BJF-treated rats. (b) Molecular function analysis of overlapping proteins between the potential targets and proteins regulated in BJF-treated rat lung tissues.

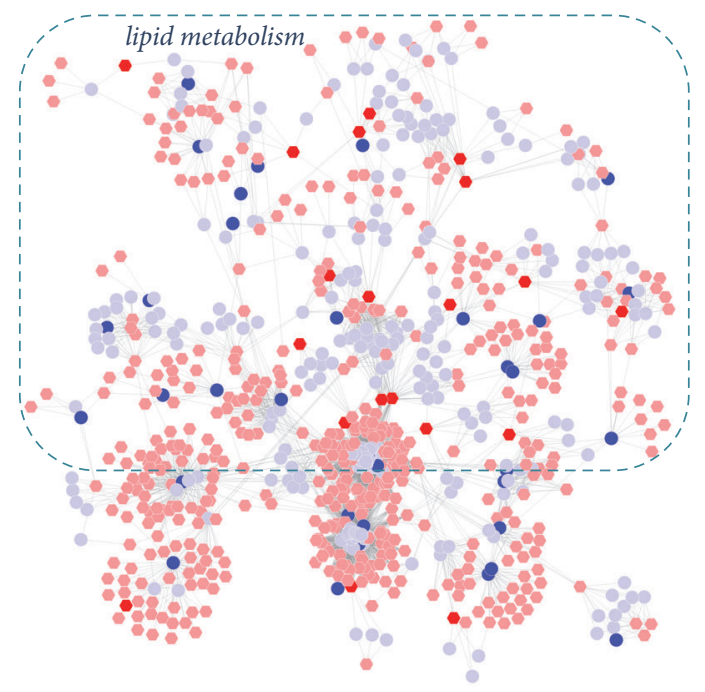

FIGURE 12: Correlation analysis of metabolites regulated in BJF-treated rats and system pharmacology target. Metscape was used to analyze the metabolite-target network (hexagon node: compounds, round node: metabolic enzymes, and edge: reactions. Red: inputted genes and proteins; blue: inputted compounds). 
Lipid metabolism
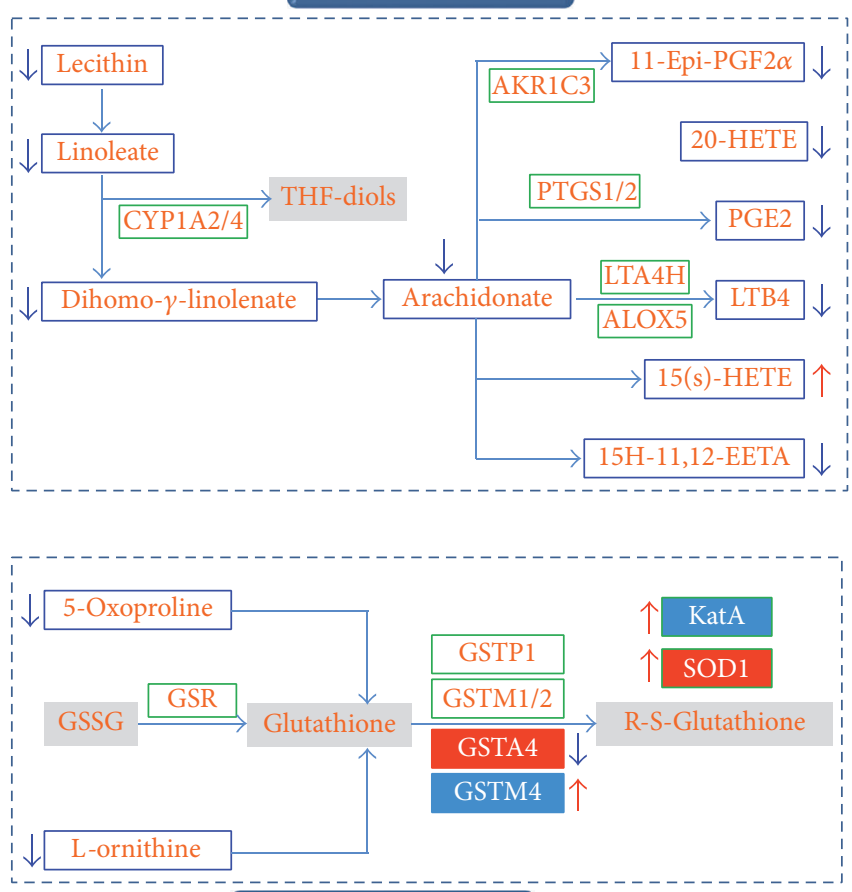

Oxidative stress

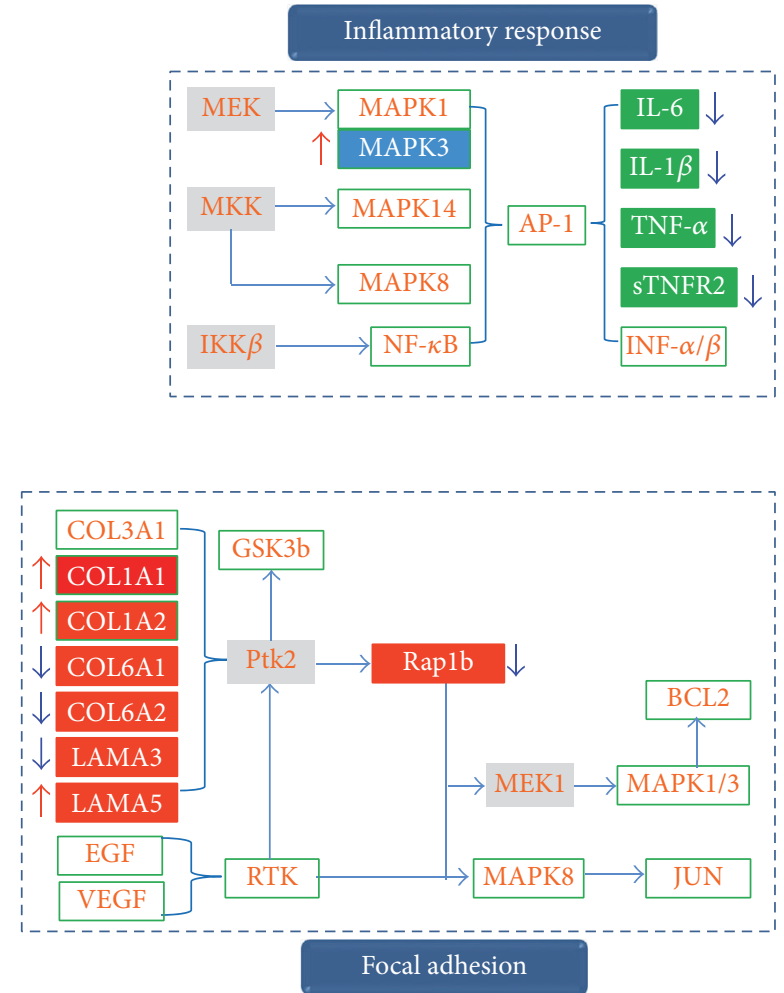

\begin{tabular}{|c|l}
\hline GSTM4 & Transcriptomics \\
\cline { 1 - 1 } COL6A2 & Proteomic \\
\cline { 1 - 1 } Lecithin & Metabolomic \\
\cline { 1 - 1 } ALOX5 & Target \\
\cline { 1 - 1 } IL-6 & In vivo experiment
\end{tabular}

MAPK14 Target + transcriptomic

COL1Al Target + proteomic

Down

$\uparrow \quad \mathrm{Up}$

FIGURE 13: Comprehensive analysis of system pharmacology targets of BJF, transcripts, proteins, and metabolites regulated in BJF-treated rat lung tissues. The targets, transcripts, proteins, and metabolites were presented as rectangles (different colors).

\section{Acknowledgments}

The research was funded by National Natural Science Foundation of China (no. 81130062).

\section{References}

[1] D. Beran, H. J. Zar, C. Perrin, A. M. Menezes, and P. Burney, "Burden of asthma and chronic obstructive pulmonary disease and access to essential medicines in low-income and middleincome countries," The Lancet Respiratory Medicine, vol. 3, no. 2, pp. 159-170, 2015.

[2] J. Vestbo, S. S. Hurd, A. G. Agustí et al., "Global strategy for the diagnosis, management, and prevention of chronic obstructive pulmonary disease GOLD executive summary," American Journal of Respiratory and Critical Care Medicine, vol. 187, no. 4, pp. 347-365, 2013.

[3] S.-Y. Li, J.-S. Li, M.-H. Wang et al., "Effects of comprehensive therapy based on traditional Chinese medicine patterns in stable chronic obstructive pulmonary disease: a four-center, openlabel, randomized, controlled study," BMC Complementary and Alternative Medicine, vol. 12, article no. 197, 2012.
[4] P. Zhao, J. Li, Y. Li, Y. Tian, Y. Wang, and C. Zheng, "Systems pharmacology-based approach for dissecting the active ingredients and potential targets of the Chinese herbal Bufei Jianpi formula for the treatment of COPD," International Journal of Chronic Obstructive Pulmonary Disease, vol. 10, no. 1, pp. 26332656, 2015 .

[5] A. Zhang, H. Sun, Z. Wang, W. Sun, P. Wang, and X. Wang, "Metabolomics: towards understanding traditional Chinese medicine," Planta Medica, vol. 76, no. 17, pp. 2026-2035, 2010.

[6] B. Li, X. Xu, X. Wang et al., "A systems biology approach to understanding the mechanisms of action of chinese herbs for treatment of cardiovascular disease," International Journal of Molecular Sciences, vol. 13, no. 10, pp. 13501-13520, 2012.

[7] W. H. M. Heijne, A. S. Kienhuis, B. Van Ommen, R. H. Stierum, and J. P. Groten, "Systems toxicology: applications of toxicogenomics, transcriptomics, proteomics and metabolomics in toxicology," Expert Review of Proteomics, vol. 2, no. 5, pp. 767780, 2005.

[8] K.-C. Tan, S. V. S. Ipcho, R. D. Trengove, R. P. Oliver, and P. S. Solomon, "Assessing the impact of transcriptomics, proteomics and metabolomics on fungal phytopathology," Molecular Plant Pathology, vol. 10, no. 5, pp. 703-715, 2009. 
[9] A. Wilmes, A. Limonciel, L. Aschauer et al., "Application of integrated transcriptomic, proteomic and metabolomic profiling for the delineation of mechanisms of drug induced cell stress," Journal of Proteomics, vol. 79, pp. 180-194, 2013.

[10] D. Meierhofer, C. Weidner, and S. Sauer, "Integrative analysis of transcriptomics, proteomics, and metabolomics data of white adipose and liver tissue of high-fat diet and rosiglitazonetreated insulin-resistant mice identified pathway alterations and molecular hubs," Journal of Proteome Research, vol. 13, no. 12, pp. 5592-5602, 2014.

[11] J. S. Li, P. Zhao, L. P. Yang, Y. Li, Y. G. Tian, and S. Y. Li, "System biology analysis of long-term effect and mechanism of Bufei Yishen on COPD revealed by system pharmacology and 3-omics profiling," Scientific Reports, vol. 6, article 25492, 2016.

[12] Q. Huang, Y. Tan, P. Yin et al., "Metabolic characterization of hepatocellular carcinoma using nontargeted tissue metabolomics," Cancer Research, vol. 73, no. 16, pp. 4992-5002, 2013.

[13] S. Maere, K. Heymans, and M. Kuiper, "BiNGO: a Cytoscape plugin to assess overrepresentation of gene ontology categories in biological networks," Bioinformatics, vol. 21, no. 16, pp. 34483449, 2005.

[14] G. Bindea, B. Mlecnik, H. Hackl et al., "ClueGO: a Cytoscape plug-in to decipher functionally grouped gene ontology and pathway annotation networks," Bioinformatics, vol. 25, no. 8, pp. 1091-1093, 2009.

[15] A. Karnovsky, T. Weymouth, T. Hull et al., "Metscape 2 bioinformatics tool for the analysis and visualization of metabolomics and gene expression data," Bioinformatics, vol. 28, no. 3, pp. 373380, 2012.

[16] J. G. Xia, I. V. Sinelnikov, B. Han, and D. S. Wishart, "MetaboAnalyst 3.0-making metabolomics more meaningful," Nucleic Acids Research, vol. 43, no. 1, pp. W251-W257, 2015.

[17] H. Magnussen and H. Watz, "Systemic inflammation in chronic obstructive pulmonary disease and asthma: relation with comorbidities," Proceedings of the American Thoracic Society, vol. 6, no. 8, pp. 648-651, 2009.

[18] W. Q. Gan, S. F. P. Man, A. Senthilselvan, and D. D. Sin, "Association between chronic obstructive pulmonary disease and systemic inflammation: a systematic review and a metaanalysis," Thorax, vol. 59, no. 7, pp. 574-580, 2004.

[19] P. J. Barnes and R. A. Stockley, "COPD: current therapeutic interventions and future approaches," European Respiratory Journal, vol. 25, no. 6, pp. 1084-1106, 2005.

[20] S. Baraldo, G. Turato, F. Lunardi et al., "Immune activation in $\alpha 1$-antitrypsin-deficiency emphysema: beyond the proteaseantiprotease paradigm," American Journal of Respiratory and Critical Care Medicine, vol. 191, no. 4, pp. 402-409, 2015.

[21] M. Kumar, N. Phougat, S. Ruhil, S. Dhankhar, M. Balhara, and A. K. Chhillar, "Genomics of chronic obstructive pulmonary disease (COPD); exploring the SNPs of protease-antiprotease pathway," Current Genomics, vol. 14, no. 3, pp. 204-213, 2013.

[22] T. Harju, V. L. Kinnula, P. Pääkkö, K. Salmenkivi, J. Risteli, and R. Kaarteenaho, "Variability in the precursor proteins of collagen I and III in different stages of COPD," Respiratory Research, vol. 11, article 165, 2010.

[23] P. Santus, A. Sola, P. Carlucci et al., "Lipid peroxidation and 5-lipoxygenase activity in chronic obstructive pulmonary disease," American Journal of Respiratory and Critical Care Medicine, vol. 171, no. 8, pp. 838-843, 2005.

[24] T. Sato, X. D. Liu, A. Nelson et al., "Reduced miR-146a increases prostaglandin E-2 in chronic obstructive pulmonary disease fibroblasts," American Journal of Respiratory and Critical Care Medicine, vol. 182, no. 8, pp. 1020-1029, 2010.

[25] A. S. Tulah, S. G. Parker, M. F. Moffatt, A. J. Wardlaw, M. J. Connolly, and I. Sayers, "The role of ALOX5AP, LTA4H and LTB4R polymorphisms in determining baseline lung function and COPD susceptibility in UK smokers," BMC Medical Genetics, vol. 12, article no. 173, 2011.

[26] A. Sunnetcioglu, H. H. Alp, B. Sertogullarından, R. Balaharoglu, and H. Gunbatar, "Evaluation of oxidative damage and antioxidant mechanisms in COPD, lung cancer, and obstructive sleep apnea syndrome," Respiratory Care, vol. 61, no. 2, pp. 205-211, 2016.

[27] I. Rahman and I. M. Adcock, "Oxidative stress and redox regulation of lung inflammation in COPD," European Respiratory Journal, vol. 28, no. 1, pp. 219-242, 2006.

[28] I. Rahman and W. MacNee, "Antioxidant pharmacological therapies for COPD," Current Opinion in Pharmacology, vol. 12, no. 3, pp. 256-265, 2012.

[29] A. Escribano, M. Amor, S. Pastor et al., "Decreased glutathione and low catalase activity contribute to oxidative stress in children with $\alpha-1$ antitrypsin deficiency," Thorax, vol. 70, no. 1, pp. 82-83, 2015.

[30] T. Turgut, N. Ilhan, F. Deveci, N. Akpolat, E. S. Erden, and M. H. Muz, "Glutathione and nitrite levels in induced sputum at COPD patients and healthy smokers," Journal of Thoracic Disease, vol. 6, no. 6, pp. 765-771, 2014. 

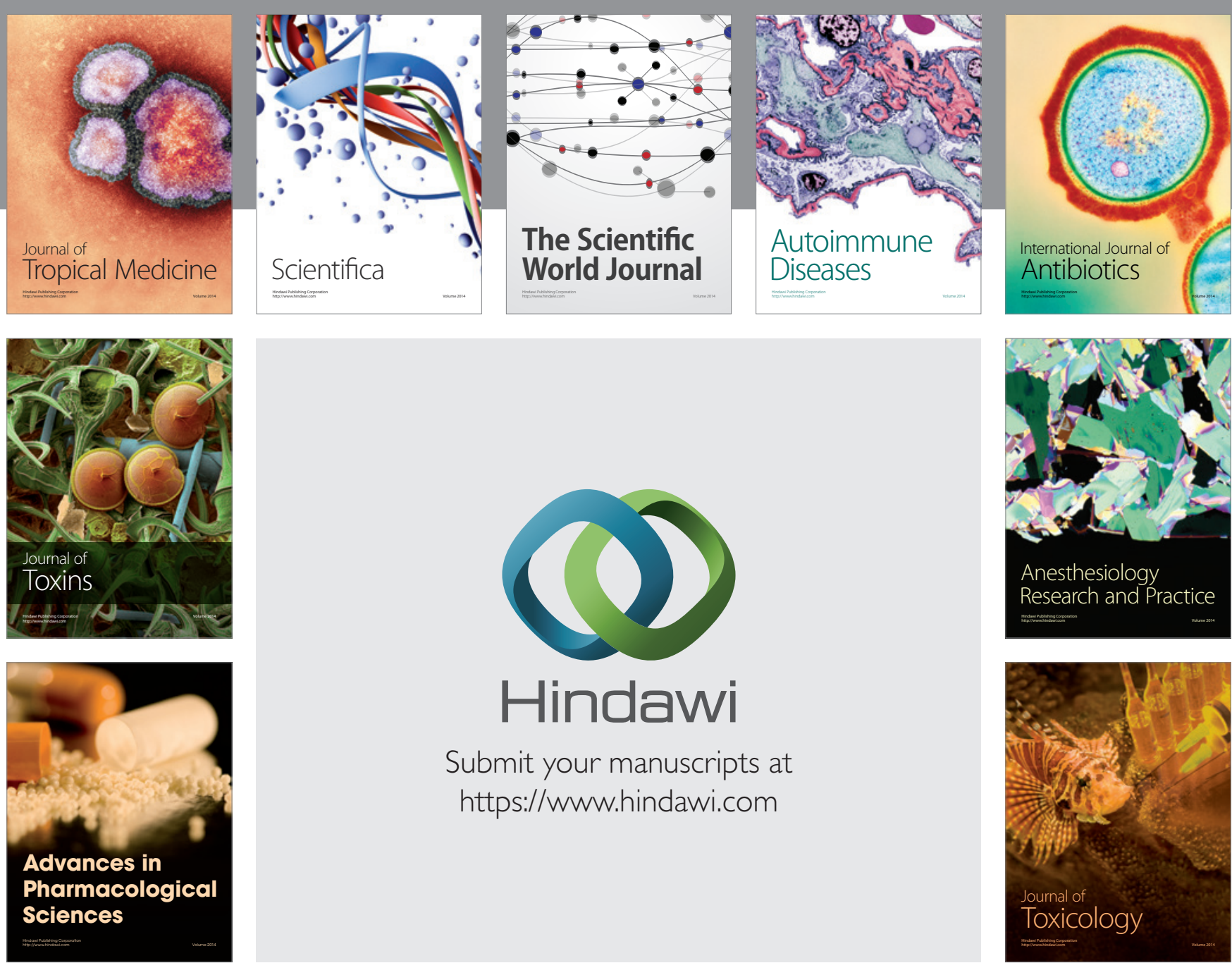

\section{Hindawi}

Submit your manuscripts at

https://www.hindawi.com
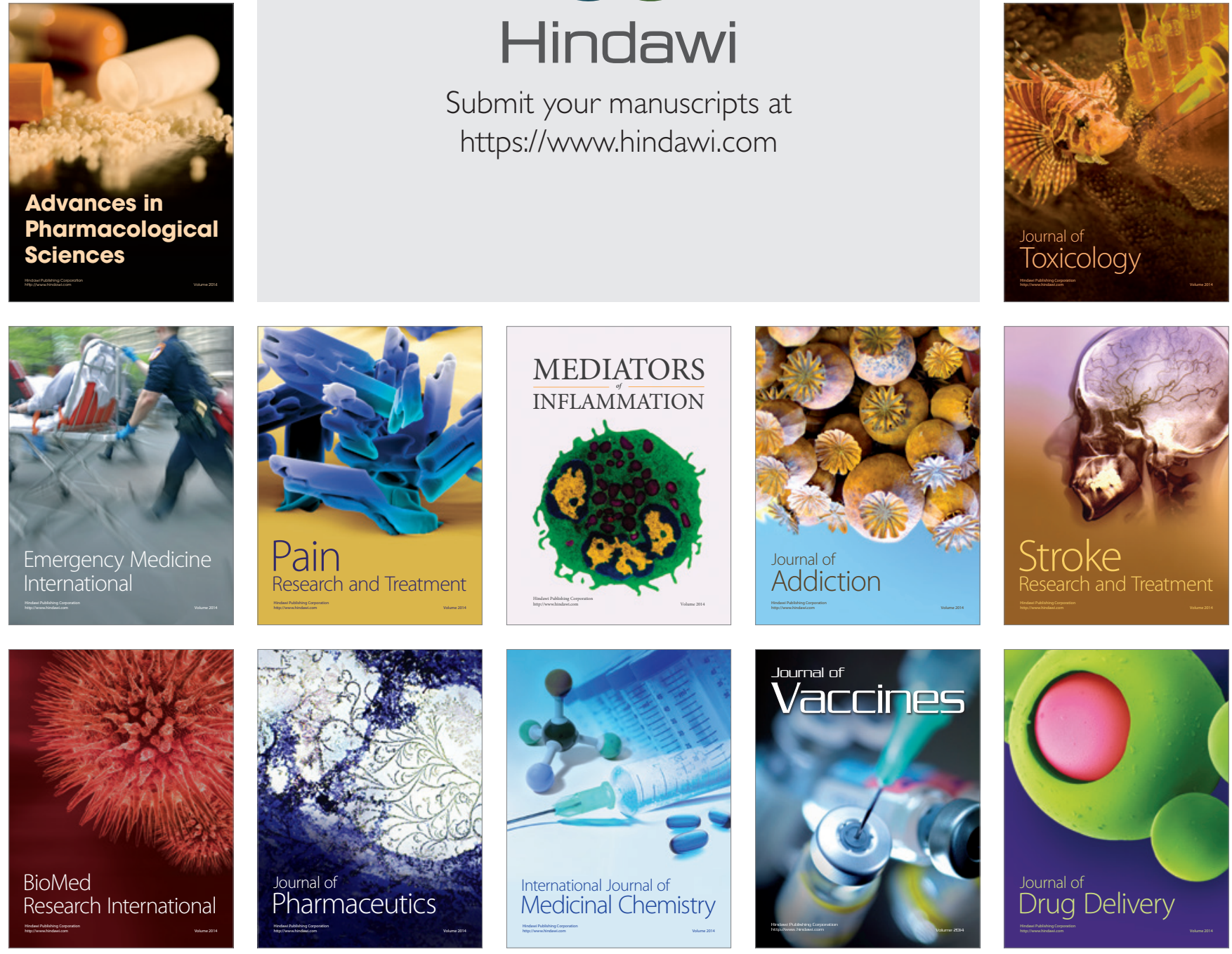